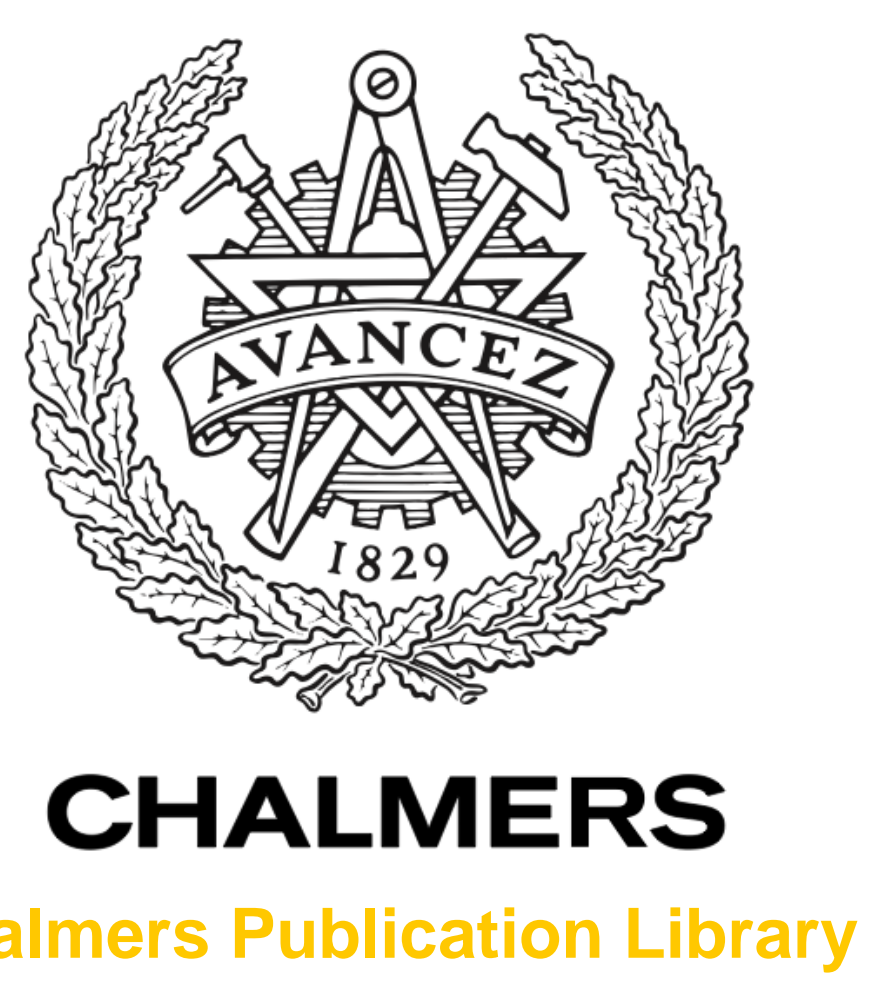

\title{
Interior insulation retrofit of a historical brick wall using vacuum insulation panels: Hygrothermal numerical simulations and laboratory investigations
}

This document has been downloaded from Chalmers Publication Library (CPL). It is the author's version of a work that was accepted for publication in:

Building and Environment (ISSN: 0360-1323)

Citation for the published paper:

Johansson, P. ; Geving, S. ; Hagentoft, C. et al. (2014) "Interior insulation retrofit of a historical brick wall using vacuum insulation panels: Hygrothermal numerical simulations and laboratory investigations". Building and Environment, vol. 79 pp. 31-45.

http://dx.doi.org/10.1016/j.buildenv.2014.04.014

Downloaded from: http://publications.lib.chalmers.se/publication/193779

Notice: Changes introduced as a result of publishing processes such as copy-editing and formatting may not be reflected in this document. For a definitive version of this work, please refer to the published source. Please note that access to the published version might require a subscription. 


\section{Interior insulation retrofit of a historical brick wall using vacuum insulation panels: Hygrothermal numerical simulations and laboratory investigations}

Pär Johansson ${ }^{1 *}$

Stig Geving ${ }^{2}$

Carl-Eric Hagentoft ${ }^{1}$

Bjørn Petter Jelle ${ }^{2,3}$

Egil Rognvik $^{3}$

Angela Sasic Kalagasidis ${ }^{1}$

Berit Time ${ }^{3}$

${ }^{1}$ Department of Civil and Environmental Engineering

Chalmers University of Technology

SE-412 96, Gothenburg

SWEDEN

${ }^{2}$ Department of Civil and Transport Engineering

Norwegian University of Science and Technology (NTNU)

NO-7491, Trondheim

NORWAY

${ }^{3}$ Department of Materials and Structures

SINTEF Building and Infrastructure

NO-7465, Trondheim

NORWAY

*Corresponding author: Pär Johansson

Direct dial: +46 317721966

Fax: +46 317721993

par.johansson@chalmers.se; par.joh@gmail.com 


\section{ABSTRACT}

Old listed buildings need to be retrofitted to reduce the energy use for heating. The possible thickness of the insulation layer is limited by the existing construction. Vacuum insulation panels (VIPs) require less thickness than conventional insulation materials to reach the same thermal resistance. Therefore, it could be more appropriate to use VIPs than conventional insulation materials when retrofitting the building envelope of listed buildings. The aim of this study is to investigate the hygrothermal performance of a brick wall with wooden beam ends after it was insulated on the interior with VIPs. One- and two-dimensional hygrothermal numerical simulations were used to design a laboratory study in a large-scale building envelope climate simulator. The wall was exposed to driving rain on the exterior surface and a temperature gradient. The relative humidity in the wall increased substantially when exposed to driving rain. The moisture content in the wooden beams also increased. There was no significant difference between the relative humidity in the wooden beam ends for the cases with and without VIPs. However, it was found that the reduced temperature in the brick after the VIPs were added led to a higher relative humidity in the wooden beams. It was also clear that when VIPs were added to the interior, the drying capacity to that side of the wall was substantially reduced. Finally, calculations of the U-value showed a large potential to reduce the energy use using VIPs on the interior of brick walls.

\section{KEYWORDS}

listed building, brick wall, interior insulation, vacuum insulation panel, hygrothermal numerical simulation, laboratory investigation 


\section{Introduction}

In Europe, the majority of the future building stock has already been built. The turnover in the building stock is low since the existing buildings fulfill a large part of the future housing demands. However, the increasing pressure to reduce the $\mathrm{CO}_{2}$ emissions and energy use in the society urge for energy efficiency measures in the existing building stock [1]. Therefore, one of the main challenges in the building sector is to find ways to reduce the energy use for heating of the existing buildings. This can be achieved by a number of measures, such as heat recovery of the ventilation air or by adding thermal insulation in the building envelope [2]. In Sweden and Norway, especially the exterior walls of old buildings, from the late 1800s to early 1900s, have a low thermal resistance compared to current standards and requirements. In Swedish buildings built before 1960 , the average $\mathrm{U}$-value of the walls is $0.58 \mathrm{~W} /\left(\mathrm{m}^{2} \cdot \mathrm{K}\right)[3]$ while it is $0.9 \mathrm{~W} /\left(\mathrm{m}^{2} \cdot \mathrm{K}\right)$ for at least 100000 Norwegian buildings from before 1945 [4]. These values should be compared to the general target $U$-value for retrofitted walls which is $0.18 \mathrm{~W} /\left(\mathrm{m}^{2} \cdot \mathrm{K}\right)$ in Sweden [5] and $0.22 \mathrm{~W} /\left(\mathrm{m}^{2} \cdot \mathrm{K}\right)$ in Norway [6]. Examples of buildings with brick walls that have been energy retrofitted have been presented by e.g. Morelli et al. [7], Weller et al. [8] and Häupl et al. [9]. As for Sweden, an overview of four listed retrofitted buildings from the 1940s to 1960s in Gothenburg was presented by Johansson [10]. All the buildings in that study had a brick façade and brick or aerated concrete walls. The retrofitting measures involved adding 30-50 $\mathrm{mm}$ glass wool on the exterior of the walls, protected by either a layer of render or a ventilated façade board. The calculated U-value was reduced from

$0.83-1.73 \mathrm{~W} /\left(\mathrm{m}^{2} \cdot \mathrm{K}\right)$ to $0.13-0.5 \mathrm{~W} /\left(\mathrm{m}^{2} \cdot \mathrm{K}\right)$ after the retrofitting, depending on the existing construction and which measure that was used. Capener et al. [11] also studied a brick building in Gothenburg which was retrofitted with an External Thermal Insulation Composite System (ETICS) involving $50 \mathrm{~mm}$ glass wool and two layers of external render.

Measurements showed a $27 \%$ reduction in energy use for heating and domestic hot water, and 
reduced moisture content in the wall. Another approach was proposed by Rasmussen [12] where $95 \mathrm{~mm}$ glass wool was added on the interior of a listed brick façade and $195 \mathrm{~mm}$ glass wool covered by render was added on the exterior of the remaining façades of a building from year 1900 in Copenhagen, Denmark.

Retrofitting of an exterior wall changes the hygrothermal performance of the wall. If it is not properly done, this could lead to damages and in worst case building failure [13]. When adding insulation to the exterior, the existing structure is kept in a warm and dry condition which is beneficial from a moisture point of view. However, the exterior wall surface becomes colder and more susceptible for moisture damages and organic growth. For example the previously mentioned ETICS, common in both new and renovated buildings in Europe, may have serious problems of biological growth causing deterioration and degradation of the exterior cladding [14]. In old brick masonry buildings the unprotected brick walls may have freeze-thaw damages. The addition of interior insulation can, in some cases, initiate freezethaw damage [15].

Many old buildings, in particular brick buildings, are considered to be of great historical value and are listed for their exterior appearance. The former Lyckholms brewery in Gothenburg, built in the late 1880s, is listed for its characteristic exterior expression [16], see Figure 1. Therefore, exterior insulation is not permitted. In fact, it is estimated that $41 \%$ of the existing buildings in Sweden are unsuitable for exterior insulation of the façade. In $31 \%$ of the existing buildings exterior insulation is permitted, while it is dubious whether it is appropriate in the remaining 28\% [17]. The situation in Norway is considered to be somewhat similar with many brick buildings unsuitable for exterior insulation. Hence, the only adequate solution to retrofit the walls of these buildings is to add interior insulation. This is a topic which has been investigated continuously during the years. Straube et al. [18] studied a number of brick buildings in the United States where interior insulation had been added and concluded that 
rain and water leakage issues have to be addressed properly and that there was a risk that wooden beam ends in the walls were damaged by the changed hygrothermal conditions in the wall. Also Künzel [13] showed that exterior walls insulated on the interior need to be combined with rain protection measures to avoid moisture induced damages.

Figure 1 somewhere here.

When retrofitting old buildings, the prerequisites are given by the existing construction. The intermediate floors in old brick buildings are often carried by wooden beams which are embedded in the brick, see Figure 1. Mold and dry rot can damage the wooden beams and the risk for that is higher when interior insulation is added because of the higher relative humidity in the wall. Inside the wall, there could be air leakage paths from the interior into the area around the wooden beam ends which can transport moist air from the interior. This will raise the moisture content even higher [19]. Also, driving rain could contribute to further raising of the moisture content in the wall and wooden beam ends, increasing the risk for moisture damages. Van den Brande et al. [20] studied the effect by rain water runoff on the water absorption of a façade. Depending on the type of material in the exterior of the façade, the additional water absorption by runoff varies. It was found that the effect was small for materials with a large capillary transport potential, such as brick and mortar. For other materials, the water absorption could be heavily underestimated since the drying of the surface is delayed by the presence of a water film on the exterior surface. In some cases the water absorption was doubled when taking the runoff into account compared to the case with no runoff.

The movement of water through the brick and mortar has many important consequences in buildings and it has therefore been studied by a number of authors, e.g. Hall [21] and Brocken [22]. While the majority of these studies involved water suction experiments from a free water surface, large-scale experiments where water suction in brick walls is studied during a real or 
artificial rain load, such as presented by Abuku et al. [23] and Piaia et al. [24], are rare. To the best knowledge of the authors, similar studies for brick masonry, as presented in this work, are not available.

A challenge when retrofitting old buildings is that the additional thickness of the wall is limited by e.g. the allowed reduction of the internal floor area. Novel highly efficient thermal insulation materials such as vacuum insulation panels (VIPs) increases the thermal resistance of the wall compared to conventional insulation materials with the same thickness. The thermal resistance of a VIP is 5-10 times higher than for conventional insulation materials [25, 26] leading to a reduced thickness in the same scale. Alternatively, a higher thermal resistance can be obtained with the same added thickness. Therefore it could be more appropriate to use VIPs than conventional insulation materials when retrofitting the building envelope of listed buildings. A laboratory study on timber frame walls retrofitted on the exterior with VIPs was presented by Sveipe et al. [27]. It was shown that a $30 \mathrm{~mm}$ thick layer of VIPs could be added to the exterior without risk of causing moisture condensation in the wall, as long as the difference between the interior and exterior vapor content, i.e. the indoor moisture supply, was below $6 \mathrm{~g} / \mathrm{m}^{3}$. This is well above the average measured indoor moisture supply for Swedish dwellings which is around 1.2-1.8 g/m $\mathrm{m}^{3}$ [3]. Pfluger et al. [28] used hygrothermal numerical simulations, laboratory investigations and field tests to investigate interior insulation of existing walls using VIPs. The results showed that interior insulation with VIPs is possible without causing moisture induced damages as long as the attachment details are designed to minimize air leakage from the interior and the façade is protected from driving rain. However, VIPs are rigid panels which, unlike most insulation materials, cannot be adapted on the construction site and have to be preordered in the correct dimensions. They are sensitive to damages which could lead to puncturing and a fivefold increase in thermal conductivity compared to the pristine state. Therefore, special care has to be taken in all stages of the 
construction process to avoid damaged VIPs. Also, thorough hygrothermal investigations are needed to ensure that the relative humidity in the wall is below the critical levels for mold growth and dry rot fungi in wood and freeze-thaw damages in the brick and mortar. However, air and moisture will diffuse through the VIP laminate during the entire service life, which hence increases the thermal conductivity of the VIPs. This has been shown with theoretical predictions and indicated by accelerated ageing experiments carried out in the laboratory [29]. As demonstrated in real building conditions, a thermal conductivity of at least $7-8 \mathrm{~mW} /(\mathrm{m} \cdot \mathrm{K})$ should be expected after 25 years $[30,31]$. However, to reach a low thermal transmittance of the building envelope with a limited insulation thickness, VIPs are the most promising alternative to date.

The aim of this study is to investigate the hygrothermal performance of a brick wall with wooden beam ends after the wall was insulated on the interior side with VIPs. Wooden beam ends were studied since these are a known risk area when insulating brick walls on the interior $[20,32,33]$. For this purpose, hygrothermal numerical simulations were performed to investigate the influential parameters for the hygrothermal performance of the wall. In an existing brick wall, it is expected that the brick and mortar have been influenced by the climate exposures with time and that cracks may occur in the construction. Due to lack of proper data, the aging of the materials in the wall was not taken into account in neither the hygrothermal numerical simulations or the laboratory study. The results of the numerical simulations were used to define an appropriate wall design, type of brick and mortar, and a climate sequence based on the real conditions in Sweden and Norway. Based on these results, the brick wall was built in the laboratory of NTNU and SINTEF Building and Infrastructure, in Trondheim according to the methods used in the late 1800 s to the early 1900 s in Sweden and Norway. The wall was tested in a large-scale building envelope climate simulator where it was exposed to a temperature gradient and cycling climate with driving rain. In the first 
sequence, the wall was insulated on the interior with VIPs. Before the second sequence, the VIPs were removed from the wall. In the work presented here, the laboratory measurement results of the two sequences with and without interior VIPs are compared to each other and with the hygrothermal numerical simulations. The study is part of a research project which is run in cooperation between Chalmers University of Technology in Gothenburg, Sweden, the Norwegian University of Science and Technology (NTNU), and SINTEF Building and Infrastructure in Trondheim, Norway.

\section{Hygrothermal numerical simulations of brick wall performance}

In this part of the study, one- and two-dimensional hygrothermal numerical simulations were used to investigate the hygrothermal performance of a brick wall. The one-dimensional simulations were used for analyzing the moisture transport through the brick only, i.e. in cases where the wall could be considered as built of a homogeneous material. In all other cases, two-dimensional simulation models have been used. The hygrothermal performance of the wall was analyzed based on the following parameters:

- Climate (temperature, relative humidity $(\mathrm{RH})$ and driving rain)

- Wall thickness

- Type of brick

- Type of mortar

- Internal thermal insulation material

The laboratory study should be based on real climate to simulate the behavior of a future fullscale retrofitting measure. Driving rain is a combination of precipitation and wind that hit the façade. The amount of moisture coming from driving rain is dependent on the angle of incidence, wind direction, wind speed and type of precipitation [34]. However, the climate 
simulator has some limitations and there is a time limitation for how long each test sequence can be run. The climate simulator generates a controlled dynamic climate condition on both sides of the brick wall. On the interior side of the wall, the temperature can be varied between $5^{\circ} \mathrm{C}$ and $50^{\circ} \mathrm{C}$ and between $-20^{\circ} \mathrm{C}$ and $80^{\circ} \mathrm{C}$ on the exterior side. The $\mathrm{RH}$ can be varied between $20 \%$ and $95 \%$ on both sides of the wall. The temperature increment and decrement rate is $0.5^{\circ} \mathrm{C} / \mathrm{min}$ for an empty chamber and the $\mathrm{RH}$ increment and decrement rate is $5 \% / \mathrm{min}$. The driving rain impacting the test wall is produced by a set of nozzles which are able to produce $15 \mu \mathrm{m}$ to $35 \mu \mathrm{m}$ large droplets with a rain intensity of $10 \mathrm{~mm} / \mathrm{h}$ to $100 \mathrm{~mm} / \mathrm{h}$, i.e. $10 \mathrm{dm}^{3} /\left(\mathrm{m}^{2} \cdot \mathrm{h}\right)$ to $100 \mathrm{dm}^{3} /\left(\mathrm{m}^{2} \cdot \mathrm{h}\right)$. The water is sprayed on the surface from the nozzles located 1 meter from the wall and pointed perpendicular to the wall surface. The nozzles are arranged so that the entire wall surface is uniformly wet. There is no additional pressure applied on the spray than from the water flow and there is no air pressure difference between the two sides of the wall. Nine metal halide global (MHG) lamps produce an artificial solar radiation with a wavelength distribution similar to that of natural outdoor solar radiation. The maximum solar intensity is $1000 \mathrm{~W} / \mathrm{m}^{2}$ which can be controlled continuously between $50 \%$ and $100 \%$ [35].

\subsection{Experiences from other investigations}

The brick walls that are targeted for this study are normally 1.5 bricks thick, i.e. $380 \mathrm{~mm}$, which is a common wall thickness in buildings from the late 1800s [36]. The walls often have a wooden beam inserted around $200 \mathrm{~mm}$ into the brick, see Figure 2. When the wall is insulated on the interior, the beam end will be in a colder environment. Rasmussen [33] used numerical simulations to find the change of temperature in the wooden beams when retrofitted on the interior and concluded that the temperature was substantially reduced. With a layer of $95 \mathrm{~mm}$ glass wool and an interior temperature of $20^{\circ} \mathrm{C}$ and $0^{\circ} \mathrm{C}$ at the exterior, the temperature was reduced from $10^{\circ} \mathrm{C}$ to $7^{\circ} \mathrm{C}$ after the wall had been insulated on the interior. If 
the moisture load is constant, the $\mathrm{RH}$ at the coldest point will increase, thus giving an increased risk of mold growth and rot in the wooden beams.

\section{Figure 2 somewhere here.}

The influence of driving rain on a brick wall insulated on the interior with $200 \mathrm{~mm}$ mineral wool was investigated numerically by Morelli and Svendsen [37]. They studied the amount of water available for capillary absorption by using the coupled heat and moisture program DELPHIN. A rain shielding factor between 0.1 and 0.5 was investigated in the study. When the façade was fully protected and no capillary absorption took place the factor was 0 and if all the rain was available for capillary absorption the factor was 1 . The driving rain showed to have a major influence on the performance of the wall where the $\mathrm{RH}$ at the beam end was studied in detail. The interior insulation reduced the temperature in the wall, leading to an increased RH from around $60 \%$ to close to $100 \%$ after 4 years in the wooden beam end. It was shown that the high moisture content in the wooden beam end could be reduced by enlarging the thermal bridge around the wooden beam by removing $300 \mathrm{~mm}$ of the insulation above and below the wooden beam, indicated by the horizontal black lines in Figure 2. Using this measure, the RH of the beam end decreased from its starting value of $85 \%$ to around $70 \%$ after 4 years. However, with a rain shielding factor of 0.5 instead of 0.1 , the RH increased to more than $95 \%$. Thus, this artificially created thermal bridge around the wooden beam is not a sufficient measure to protect the beam end from high moisture contents created by the driving rain.

As mentioned above, brick walls exposed to driving rain may be damaged by freeze-thaw action. Also bricks that are "freeze-thaw resistant" can be damaged if too high moisture levels occur in the wall during the freeze-thaw cycles [15]. The water in the capillaries of the brick expands when it freezes and after a number of cycles the structure starts to disintegrate.

Mensinga et al. [15] studied the risk of frost damage of bricks subjected to freeze-thaw cycles 
in a retrofitted wall. A risk assessment methodology based on frost dilatometry was developed where the critical level of moisture saturation for freeze-thaw damage could be found. They experienced that the critical degree of saturation (defined as the ratio between the moisture content and the moisture content when all accessible pores were filled with water) varied from 0.25 to 0.8 for two different investigated types of brick. The lower value was for a historical Canadian brick and the higher value for a modern Canadian extruded clay brick. The wide variation shows the importance of having information on the actual performance of the brick in the wall to ensure a safe moisture state after the retrofitting.

\subsection{Hygrothermal properties of brick and mortar in numerical simulations}

To evaluate the impact of the hygrothermal properties of the brick and mortar used in the laboratory study, four types of bricks and six types of mortars were used in the numerical simulations. The thermal conductivity and specific heat capacity of the brick and mortar were $0.6 \mathrm{~W} /(\mathrm{m} \cdot \mathrm{K})$ and $850 \mathrm{~J} /(\mathrm{kg} \cdot \mathrm{K})$ respectively. The size of the bricks was $250 \mathrm{~mm}$ x $120 \mathrm{~mm}$ x $62 \mathrm{~mm}$ (length $\mathrm{x}$ width x height) with 10-12 mm thick mortar joints between the bricks. The density, $\rho\left(\mathrm{kg} / \mathrm{m}^{3}\right)$, porosity, $P(-)$, water vapor diffusion resistance factor, $\mu(-)$, and liquid water transport coefficient, $D_{w s}\left(\mathrm{~m}^{2} / \mathrm{s}\right)$, at $80 \% \mathrm{RH}$ and at saturation, for the brick and mortar are presented in Table 1. The moisture sorption isotherms of the bricks are presented in Figure 3.

\section{Table 1 somewhere here.}

Figure 3 somewhere here.

To resemble the properties of an old brick wall in the laboratory study it was essential to use a brick and mortar similar to what was used in Sweden and Norway in the late 1800s to the early 1900s. The modern types of brick are formed by mechanical dry-pressing, molding or extruding the clay to form the wanted size and shape [41], giving other properties to the bricks 
than what manual production methods does. The highest moisture storage capacity (i.e. the highest moisture content at any given RH in Figure 3) was found for the brick measured in the laboratory. It was close to the moisture storage capacity of "Masonry brick" which is a brick masonry including mortar joints. The modern bricks have a moisture storage capacity close to "Extruded brick". This is also similar to the properties of "Vienna 1900s" which is a brick produced in the 1900s in Vienna. The "Historical brick" is an inhomogeneous brick from the 1500s in Stralsund, Germany, and "Hand-formed brick" is a new brick produced using the old manufacturing process [38]. The moisture storage capacity shows that the "Masonry brick", "Vienna 1900s" and "Extruded brick" have the highest moisture content in the hygroscopic moisture range, i.e. up to $98 \% \mathrm{RH}$. Another difference between the brick types is the liquid water transport coefficient. Of the six bricks presented in Table 1, this parameter varies between $1.7 \mathrm{~m}^{2} / \mathrm{s}$ and $300 \mathrm{~m}^{2} / \mathrm{s}$. The liquid water transport coefficient is substantially higher for the "Historical brick" and "Hand-formed brick" than for the "Masonry brick" and "Extruded brick". Also, the water vapor diffusion resistance factor is higher for the "Historical brick" and "Hand-formed brick". The four types of bricks used in the numerical simulation study can be divided into two main groups where the "Historical brick" and "Hand-formed brick" have similar hygrothermal properties, while the "Masonry brick" and "Extruded brick" have properties more similar to modern bricks.

In the early 1900s, hydraulic lime mortar was used in brick masonry buildings. While appreciated for its large tolerance to movements caused by temperature and moisture fluctuations, one of the disadvantages is the longer curing time required compared to mixtures of lime and cement mortar. In the laboratory study, one of the limitations is the time for the construction of the wall. Therefore, a mortar with a short curing and adhesion time is desired but with similar hygrothermal properties as the hydraulic lime mortar. As can be seen in Table 1, the main difference between the six mortars is the liquid water transport coefficient which 
is substantially higher for the lime cement mortars and hydraulic lime mortars than for the pure cement mortars. This is caused by the larger pore structure in the cement mortars which reduces the capillary suction potential through the mortar [22]. Also the water vapor diffusion resistance factor is lower for the cement mortars than for the two other types of mortar. The difference between the two cement mortars, type $\mathrm{N}$ and type $\mathrm{S}$, is mainly in the final strength. Cement type $\mathrm{S}$ has higher final strength than type $\mathrm{N}$. Therefore type $\mathrm{N}$ is normally used in masonry work and type $\mathrm{S}$ is used in applications where a stronger adhesion is required [42]. The "Extruded brick" in Table 1 with a 10-12 mm thick layer of coarse lime cement mortar between the bricks (number 1 in Figure 2) was chosen for the following numerical simulations.

\subsection{Climate load at the wall location}

In the laboratory study it is essential to choose a climate sequence which resembles the conditions at the location of the reference wall to make useful conclusions. The two cities Gothenburg and Bergen are situated on the west coast of Sweden and Norway, respectively. Therefore they are two of the cities in Scandinavia with the highest exposure to driving rain. This means the driving rain is of great importance for the hygrothermal performance and risk of damages to the brick constructions in these two cities. The annual average rain fall in Bergen is $2421 \mathrm{~mm}$ and in Gothenburg $1074 \mathrm{~mm}$ [38]. However, the number of hours with a driving rain load of more than $1 \mathrm{~mm} / \mathrm{h}$, i.e. $1 \mathrm{dm}^{3} /\left(\mathrm{m}^{2} \cdot \mathrm{h}\right)$, during 2004 on an exposed façade in Gothenburg, was $64 \mathrm{~h}$. The calculated average driving rain intensity during these rain events was on average $1.9 \mathrm{~mm} / \mathrm{h}$, i.e. $1.9 \mathrm{dm}^{3} /\left(\mathrm{m}^{2} \cdot \mathrm{h}\right)$, and the maximum exposure was $7 \mathrm{~mm} / \mathrm{h}$, i.e. $7 \mathrm{dm}^{3} /\left(\mathrm{m}^{2} \cdot \mathrm{h}\right)$. The driving rain intensity was calculated based on the wind direction, wind speed and the amount of rain fall. The rain load in the laboratory study was around $5 \mathrm{~mm} / \mathrm{h}$, i.e. $5 \mathrm{dm}^{3} /\left(\mathrm{m}^{2} \cdot h\right)$. Högberg [34] studied a number of rain events where driving rain occurred and found that the measured average wind speed varied around 8-9 m/s for rain intensities of 
$0.5-1.4 \mathrm{~mm} / \mathrm{h}$, i.e. $0.5-1.4 \mathrm{dm}^{3} /\left(\mathrm{m}^{2} \cdot \mathrm{h}\right)$, leading to $0.1-0.5 \mathrm{~mm} / \mathrm{h}$, i.e. $0.1-0.5 \mathrm{dm}^{3} /\left(\mathrm{m}^{2} \cdot \mathrm{h}\right)$, of driving rain. During heavier rain loads of 3-4.5 mm/h, i.e. $3-4.5 \mathrm{dm}^{3} /\left(\mathrm{m}^{2} \cdot \mathrm{h}\right)$, the wind was around 3.9-7 m/s. This led to a driving rain load of $1-3 \mathrm{~mm} / \mathrm{h}$, i.e. $1-3 \mathrm{dm}^{3} /\left(\mathrm{m}^{2} \cdot \mathrm{h}\right)$. Nore et al. [43] found similar results for measurements of driving rain events in Trondheim, Norway. These rain loads correspond well with the calculated driving rain loads used in the hygrothermal numerical simulations and in the laboratory study.

To evaluate the influence by the climate at the wall location, a $380 \mathrm{~mm}$ brick wall in Bergen and Gothenburg was studied. The two-dimensional heat and moisture transfer was calculated using the numerical simulation tool WUFI 2D [38]. This software solves coupled heat and moisture transport equations by finite volumes where the temperature and relative humidity are the driving potential for the heat and moisture transport through the material. The interior climate was based on the outdoor climate in Bergen and Gothenburg respectively, with a normal moisture load as defined by SS-EN 15026 [44]. The interior surface heat transfer coefficient, $h\left(\mathrm{~W} /\left(\mathrm{m}^{2} \cdot \mathrm{K}\right)\right)$, was set to $8 \mathrm{~W} /\left(\mathrm{m}^{2} \cdot \mathrm{K}\right)$ in conformity with SS-EN ISO 6946:2007 [45]. The interior water vapor surface transfer coefficient was calculated by combining the water vapor surface transfer coefficient at the interior surface (corresponding to a $s_{d}$-value of $0.006 \mathrm{~m}$ ) and the water vapor transfer coefficient of a wall finishing with a $s_{d}$-value of $3 \mathrm{~m}$. The latter corresponds to a moisture resistance of a kraft paper covering a gypsum board in terms of the equivalent stagnant air layer thickness. The exterior surface heat transfer coefficient was $25 \mathrm{~W} /\left(\mathrm{m}^{2} \cdot \mathrm{K}\right)$ [45] with a wind dependent water vapor surface transfer coefficient, and the initial conditions of the materials were $15^{\circ} \mathrm{C}$ and $70 \% \mathrm{RH}$.

The rain water hitting the façade, available for capillary absorption, is determined by the rain water absorption factor. When the façade is fully protected and no capillary absorption takes place the factor is 0 and, if all the rain is available for capillary absorption, the factor is 1 . In WUFI 2D a rain water absorption factor of 0.7 is considered to be adequate for moderately 
exposed walls [38]. For this numerical simulation, the wall was considered to be protected from most of the rain with a rain water absorption factor of 0.3 . This rain water absorption factor is not supported by experimental data. It was chosen to allow a comparison between protected walls in the two cities without a too high moisture load on the wall. The rain water absorption factor of 0.7 gave a fast moisture accumulation in both cities. The dominant wind direction for both Bergen and Gothenburg is south which, therefore, was chosen as the direction of the wall. The numerical simulation results for the two cities of the total moisture content in the wall and the RH in the middle of the wall are shown in Figure 4.

Figure 4 somewhere here.

The dominating moisture source is from the rain on the façade which means the materials will be wet and the moisture transported by capillary suction. During the simulated five-year period, the inward capillary moisture transport is 4 and 1.7 times larger than the moisture transported by diffusion through the middle of the wall in Bergen and Gothenburg, respectively. The $\mathrm{RH}$ in the middle of the wall in Bergen was close to $100 \%$ already after 1 year of numerical simulation. The brick wall in Gothenburg was not exposed to the same rain load as in Bergen. Here, the RH in the middle of the wall peaked at 88\% in August of year 5. Also, the total moisture content in the wall in Bergen increased rapidly during the first years of the numerical simulation to stabilize during year 4 and 5. The maximum moisture content was $147 \mathrm{~kg} / \mathrm{m}^{3}$ in December of year 4. For the wall in Gothenburg, the moisture content was $48 \mathrm{~kg} / \mathrm{m}^{3}$ at maximum. However, the water was not evenly distributed in the walls. At the exterior surface of the brick, where there could be a risk of freeze-thaw damages, the moisture content was significantly higher. It was peaking at $298 \mathrm{~kg} / \mathrm{m}^{3}$ in Bergen and $211 \mathrm{~kg} / \mathrm{m}^{3}$ in Gothenburg which should be compared to the saturation moisture content of the brick which was $370 \mathrm{~kg} / \mathrm{m}^{3}$. This gives a degree of saturation of 0.4 in Bergen and 0.13 in Gothenburg. However, the critical degree of saturation, i.e. when there is a risk of freeze-thaw damages in 
the brick, is not known for most bricks. This was also the case for the bricks in these numerical simulations. As mentioned before, laboratory measurements have shown that the critical degree of saturation for freeze-thaw damages can be in the range of $0.25-0.8$ [15]. The number of freeze-thaw cycles in the exterior surface of the wall during the simulated year also differed between the two cities. It was 16 freeze-thaw cycles in Bergen and 35 in Gothenburg. The combination of frequent freeze-thaw cycles and unprotected brick façades could explain why many brick buildings in Gothenburg have freeze-thaw damages on the most exposed parts. This was noted e.g. in the residential area Torpa in Gothenburg, where the upper part of many brick façades has been covered by corrugated steel for protection [46]. Thus, in case the brick is unprotected from driving rain, the moisture content in the middle of the wall will be very high, even before it is retrofitted.

\subsection{Selection of wall thickness}

A limitation in the laboratory study was the thickness of the wall. The thickness is limited by the weight that could be lifted by a crane, and the time for wetting and drying of the wall. Hygrothermal numerical simulations were used to estimate how long testing period the full wall thickness would require and if it was possible to reduce the thickness in the laboratory study. The hypothesis was that the same hygrothermal mechanisms would take place in the wall, independent of the thickness, and that only the time scale would be influenced. This hypothesis is further investigated by one-dimensional numerical simulations of a homogeneous brick wall (number 2 in Figure 2). The interior and exterior climates were based on the HAMSTAD [47] benchmark project where the moisture accumulation in a brick wall was studied during consecutive periods of sun and rain loads on the wall, see Figure 5.

Figure 5 somewhere here. 
Note that the climate is fictitious and the exterior $\mathrm{RH}$ is fixed at $90 \%$. The initial conditions of the materials were $20^{\circ} \mathrm{C}$ and $50 \% \mathrm{RH}$. The interior surface heat transfer coefficient was $8 \mathrm{~W} /\left(\mathrm{m}^{2} \cdot \mathrm{K}\right)$ and the interior $s_{d}$-value was $0.2 \mathrm{~m}$, equivalent to an interior mortar layer. The exterior surface heat transfer coefficient was $25 \mathrm{~W} /\left(\mathrm{m}^{2} \cdot \mathrm{K}\right)$ with a wind dependent water vapor surface transfer coefficient. The rain water absorption factor was 1, i.e. all rain was available for capillary absorption. With this climate load, the relative humidity in the entire wall increases with time. In this part of the study, the location $60 \mathrm{~mm}$ from the interior surface of the brick was chosen as the monitoring location. This choice was done after a comparison of the RH increase at the locations $30 \mathrm{~mm}, 60 \mathrm{~mm}$ and $90 \mathrm{~mm}$ from the interior surface of the brick. It was found that the conclusions were similar for all monitored locations. Since the location $60 \mathrm{~mm}$ from the interior surface corresponds to the middle of the $120 \mathrm{~mm}$ thick wall, this location was chosen for the further study. Figure 6 shows the RH at the location $60 \mathrm{~mm}$ from the interior surface in the brick in walls of three different thicknesses with alternatively "Historical brick" or "Masonry brick". As comparison, the $250 \mathrm{~mm}$ and $380 \mathrm{~mm}$ "Masonry brick" walls were simulated both with and without the solar radiation in the climate cycle in Figure 5.

Figure 6 somewhere here.

As expected, it took longer time for the thicker walls to get saturated at the point $60 \mathrm{~mm}$ from the interior surface of the brick. For the "Historical brick" wall of $380 \mathrm{~mm}$ thickness it took $173 \mathrm{~h}$. For the $250 \mathrm{~mm}$ and $120 \mathrm{~mm}$ thick walls it took $87 \mathrm{~h}$ and $53 \mathrm{~h}$, respectively. This was $50 \%$ and $30 \%$ of the time for the thickest wall. A similar relation was observed for the "Masonry brick" wall. The $380 \mathrm{~mm}$ wall was saturated after $578 \mathrm{~h}$ while the $250 \mathrm{~mm}$ and $120 \mathrm{~mm}$ thick walls took $218 \mathrm{~h}$ and $64 \mathrm{~h}$ to reach saturation. Compared to the time for the thickest wall, this was $38 \%$ and $11 \%$, respectively. Despite the differences in the time of wetting, the same water inflow was found during the wetting of the different wall thicknesses. 
Thus, it is concluded that a thinner wall can be used in the laboratory study and that the time scale has to be determined based on the permeability of the bricks.

It was the RH at the point $60 \mathrm{~mm}$ from the interior surface of the brick that was monitored. Therefore, the distance the water had to be transported through the brick wall before reaching the monitored location varied for the three walls with different thicknesses. In the $380 \mathrm{~mm}$ wall the water had to be transported through $320 \mathrm{~mm}$ brick, in the $250 \mathrm{~mm}$ wall through $190 \mathrm{~mm}$ brick and in the $120 \mathrm{~mm}$ wall through $60 \mathrm{~mm}$ brick to reach the monitored location. The relation between the time of saturation and the wall thickness was not linear. However, using the square root of the time of saturation and the thickness of the wall on the exterior of the monitored location, a proportional relation was found. For the "Historical brick" the relation is $\sqrt{t}=23 \cdot d+5.6$ and $\sqrt{t}=62 \cdot d+3.9$ for the "Masonry brick", where $t(\mathrm{~h})$ is the time before saturation and $d(\mathrm{~m})$ is the thickness of the wall on the exterior of the monitored location. This relation can be compared to the analytical solution for a water uptake experiment, $\Delta m_{t}=A_{w} \cdot \sqrt{t}\left(\mathrm{~kg} / \mathrm{m}^{2}\right)$, where $\Delta m_{t}\left(\mathrm{~kg} / \mathrm{m}^{2}\right)$ is the mass gain after time $t$ (s) and $A_{w}\left(\mathrm{~kg} /\left(\mathrm{m}^{2} \cdot \mathrm{s}^{0.5}\right)\right)$ is the water absorption coefficient [39]. Assuming that the thickness of the material is proportional to the mass gain, then the thickness is also proportional to the square root of the time. The coefficient of determination, i.e. how well the data points fits to the equation, for the two equations and the numerical simulations is 0.97 and 0.99 for the "Historical brick" and "Masonry brick" respectively.

\subsection{Final selection of brick and mortar}

In Figure 6, it was shown that the type of brick in the wall, together with the wall thickness, influences the time required for saturation of the wall. As discussed earlier, this is caused by the fact that modern bricks, e.g. "Masonry brick" and "Extruded brick", are less capillary active than hand-formed bricks manufactured many years ago, e.g. "Historical brick" and 
"Hand-formed brick". In the past it was common to use different brick qualities over the depth of the wall. In the façade, a brick of better quality, i.e. less capillary active and more resistant to freeze-thaw cycles, could be used while the inner part of the wall could be made of bricks with lower quality. Here, the simplified one-dimensional case of a $250 \mathrm{~mm}$ thick brick wall with the same brick type in the whole wall is numerically simulated. The bricks are separated by a vertical $10 \mathrm{~mm}$ thick layer of fine lime cement mortar (number 3 in Figure 2). The four brick types in Table 1 were numerically simulated using the same initial conditions and boundary conditions as in the previous section. From the results it can be seen that the difference between the bricks was as clear as in Figure 6. The time before the walls were saturated with moisture at the point $60 \mathrm{~mm}$ from the interior ranged from $99 \mathrm{~h}$ and $108 \mathrm{~h}$ for "Hand-formed brick" and "Historical brick" to $217 \mathrm{~h}$ for "Extruded brick" and $588 \mathrm{~h}$ for "Masonry brick". These largely different time scales confirm that it is important to have good knowledge of the hygrothermal properties of the specific type of bricks to predict the results of the laboratory study.

Obviously, it is not only the type of brick and the wall thickness that determine the moisture properties of the wall, but also the type of mortar between the bricks. To investigate the required drying time for the wall after the wetting sequence, a wall placed indoors, exposed to the laboratory environment on both sides, was numerically simulated. The wall consisted of "Extruded brick" with a 10-12 mm thick layer of one of the six mortars in Table 1 between the bricks (number 4 in Figure 2). Only the type of mortar was varied in the different numerical simulations. The starting condition was a mortar at $20^{\circ} \mathrm{C}$ with $98 \% \mathrm{RH}$, and brick at $20^{\circ} \mathrm{C}$ with $80 \% \mathrm{RH}$. The drying period started on October 1 and the laboratory was assumed to have a normal moisture load as defined by EN 15026 [44]. The climate was on average $20^{\circ} \mathrm{C}$ and $42.3 \% \mathrm{RH}$ with a surface heat transfer coefficient of $8 \mathrm{~W} /\left(\mathrm{m}^{2} \cdot \mathrm{K}\right)$ and a sdvalue of $0.006 \mathrm{~m}$ on both sides. For comparison, a homogenous "Extruded brick" wall was 
numerically simulated at the same conditions. The changing RH in the middle of the walls is presented in Figure 7.

Figure 7 somewhere here.

The walls with the cement mortars $(\mathrm{C})$ gave a very slow drying process. The $\mathrm{RH}$ in the walls had only been reduced by 3 percentage points, i.e. to $95 \%$ after 1344 hours ( 8 weeks) of drying. The wall without mortar and only "Extruded brick" also had a slow drying during the first 1008 hours (6 weeks), but after that it dried quickly down to $83 \%$. For the walls with the lime cement mortar (LC) and hydraulic lime mortars (L) the drying was much faster. In the wall with the fine hydraulic lime mortar (L), the $\mathrm{RH}$ was reduced to below $70 \%$ after 1344 hours ( 8 weeks). There was also a difference between the walls with the coarse and fine versions of the same mortar. However, the difference was smaller after 1344 hours (8 weeks) compared to the difference between the lime cement (LC) and hydraulic lime (L) mortars. It is clear that the mortar between the bricks shortens the drying process of the wall. This could be explained by the smaller capillaries in the mortar than in the brick, leading to a higher water transport and a faster drying. The mortar could also have an influence on the moisture content in the wall during the wetting phase which was simulated numerically with only one type of mortar. Hydraulic lime mortar requires a longer curing time than a mixture of lime and cement mortar would. It was also expected to be more difficult to fully control the adhesion of the hydraulic lime mortar. Therefore, a lime and cement mortar was chosen for the laboratory study. It fairly resembles the hygrothermal properties of the historical hydraulic lime mortar and it minimizes the curing and adhesion times, allowing for a faster construction.

\subsection{Influence by the thermal insulation material}

One aim of this study was to investigate what will happen in the old construction when the hygrothermal performance is changed by adding interior insulation. The thermal conductivity 
of the VIPs was $0.005 \mathrm{~W} /(\mathrm{m} \cdot \mathrm{K})$ and the thickness of the VIP layer was $20 \mathrm{~mm}$ which corresponds to an interior surface heat transfer coefficient of $0.242 \mathrm{~W} /\left(\mathrm{m}^{2} \cdot \mathrm{K}\right)$. This gives a theoretical U-value of $0.21 \mathrm{~W} /\left(\mathrm{m}^{2} \cdot \mathrm{K}\right)$ compared to $1.28 \mathrm{~W} /\left(\mathrm{m}^{2} \cdot \mathrm{K}\right)$ for the wall without VIPs. However, if the wall gets saturated with moisture the U-value increases to $2.94 \mathrm{~W} /\left(\mathrm{m}^{2} \cdot \mathrm{K}\right)$ for the wall without VIPs but only to $0.23 \mathrm{~W} /\left(\mathrm{m}^{2} \cdot \mathrm{K}\right)$ for the wall with VIPs. This means that the $20 \mathrm{~mm}$ VIPs decreases the U-value with 84-92\% compared to the wall without VIPs.

However, it is not possible to install a continuous VIP layer on the interior of the wall because of the wooden beams and intermediate floor connections to the wall. These thermal bridges increases the average $\mathrm{U}$-value to $0.49 \mathrm{~W} /\left(\mathrm{m}^{2} \cdot \mathrm{K}\right)$ which means the reduction of the $\mathrm{U}$-value for the dry brick wall becomes $62 \%$. Considering that around two-thirds of the heat losses in multi-family buildings in Sweden are accounted for by the transmission losses through the walls and windows [16], the potential reduction of the total energy use for heating becomes around $30 \%$ if a layer of $20 \mathrm{~mm}$ VIPs is installed on the interior of a façade with $20 \%$ windows.

The numerically simulated brick wall was $250 \mathrm{~mm}$ thick with historical bricks, separated by a vertical $10 \mathrm{~mm}$ thick layer of fine lime cement mortar (number 3 in Figure 2). Four different cases were numerically simulated where (1) the wall without interior insulation ( $\left.h=8 \mathrm{~W} /\left(\mathrm{m}^{2} \cdot \mathrm{K}\right), s_{d}=0.2 \mathrm{~m}\right)$ was compared to the cases of (2) only adding a vapor barrier to the interior of the wall $\left(h=8 \mathrm{~W} /\left(\mathrm{m}^{2} \cdot \mathrm{K}\right), s_{d}=1500 \mathrm{~m}\right),(3)$ adding a vapor open interior insulation $\left(h=0.242 \mathrm{~W} /\left(\mathrm{m}^{2} \cdot \mathrm{K}\right), s_{d}=0.2 \mathrm{~m}\right)$ and (4) adding VIPs which function in the same way as a vapor barrier $\left(h=0.242 \mathrm{~W} /\left(\mathrm{m}^{2} \cdot \mathrm{K}\right), s_{d}=1500 \mathrm{~m}\right)$. The initial conditions of the materials were $20^{\circ} \mathrm{C}$ and $50 \% \mathrm{RH}$ and the interior climate was $20^{\circ} \mathrm{C}$ and $40 \% \mathrm{RH}$. The exterior climate was based on the HAMSTAD benchmark, shown in Figure 5, with an exterior surface heat transfer coefficient of $25 \mathrm{~W} /\left(\mathrm{m}^{2} \cdot \mathrm{K}\right)$ and a wind dependent vapor surface transfer coefficient. The walls were well protected with a rain water absorption factor of 0.1 , i.e. a 
small amount of rain was available for capillary absorption assuming that the remaining water runs down the façade or splashes off at impact. The results from the one-dimensional numerical simulations of the four cases are shown in Figure 8.

Figure 8 somewhere here.

Adding a vapor barrier to the interior of the brick wall does not change the total moisture content in the wall compared to the case without the vapor barrier. However, at the location $60 \mathrm{~mm}$ from the interior surface of the brick, the $\mathrm{RH}$ is higher than without the vapor barrier. This is caused by the restricted drying from the interior surface of the wall. In the two walls with a layer of interior insulation, both the $\mathrm{RH}$ and the moisture content increases compared to the case without interior insulation. The wall with the vapor open insulation has a slightly lower RH and moisture content than the wall with VIPs. The main part of the vapor and water flow in the wall is caused by the rain on the exterior surface. Thus, the indoor moisture load is of minor importance for the conditions studied here.

\section{Wall construction, instrumentation and climate in the laboratory study}

The hygrothermal numerical simulations showed that the same conclusions could be drawn by using a $250 \mathrm{~mm}$ thick brick wall as for the full wall thickness of $380 \mathrm{~mm}$. It was also found that the time before the wall was saturated with moisture at the point $60 \mathrm{~mm}$ from the interior surface of the brick differed with a factor of 6 depending on the type of brick in the wall. Therefore a brick with a high liquid transport coefficient, similar to the "Historical brick", was chosen. The mortar selection was also based on the hygrothermal numerical simulations. It was shown that the difference between using hydraulic lime mortar and lime cement mortar was acceptable, thus lime cement mortar was chosen for the laboratory study. To study the effect by the interior insulation on the brick wall with the wooden beam ends in the laboratory, the rain load on the wall should not be too high compared to the climate on the 
wall location, as described in Section 2.3 and Section 2.4. With all these parameters defined, the wall was built, equipped with hygrothermal sensors and tested in the large-scale building envelope climate simulator.

\subsection{Measured hygrothermal properties of the brick and mortar}

Before the wall was built, the hygrothermal properties of the brick and mortar were measured in the laboratory of NTNU and SINTEF Building and Infrastructure. The properties given in datasheets provided by the material producers were used as reference. The procedures in the standards NS-EN ISO 15148 [39] and NS-EN 1015-18 [40] were followed using 6 samples each of the brick and mortar. The average values and uncertainties for the brick and mortar are presented in Table 2 .

\section{Table 2 somewhere here.}

The $A_{w}$-value is defined in NS-EN ISO 15148 [39] as the short term liquid water absorption coefficient. This is a measure of the rate of water absorption by e.g. driving rain on a material surface. To assess the liquid water transport coefficient, $D_{w s}\left(\mathrm{~m}^{2} / \mathrm{s}\right)$, dependent on the moisture content, $w\left(\mathrm{~kg} / \mathrm{m}^{3}\right)$, there is an approximate relation between $A_{w}$ and $D_{w s}$ which is used in WUFI 2D [38]:

$D_{w s}(w)=3.8 \cdot\left(\frac{A_{w}}{w_{f}}\right)^{2} \cdot 1000^{\frac{w}{w_{f}}-1}\left(\mathrm{~m}^{2} / \mathrm{s}\right)$

where $A_{w}$ is the short term liquid water absorption coefficient, $w$ is the moisture content and $w_{f}$ is the moisture content at saturation. In order to use Equation (1), the moisture sorption isotherm for the material has to be defined. The approximate equation for the sorption isotherm based on the measured data is [38]:

$$
w(\varphi)=w_{f} \cdot \frac{(b-1) \cdot \varphi}{b-\varphi}\left(\mathrm{kg} / \mathrm{m}^{3}\right)
$$


where $b(-)$ is a fitting parameter and $\varphi(-)$ is the $\mathrm{RH}$. The resulting sorption isotherm is presented in Figure 3. Obviously, the moisture properties of the brick are different depending on where and when it was produced. The properties are also changing with time as the material is exposed to different climate conditions and freeze-thaw cycles. It is therefore difficult to predict the hygrothermal properties of the brick wall without testing the actual materials in the building.

The liquid water transport coefficient was calculated using Equation (1), based on the laboratory measurement results for the brick and mortar. The liquid water transport coefficient at $80 \% \mathrm{RH}$ and at saturation are presented in Table 1 for the brick measured in the laboratory compared to the data from WUFI 2D [38]. For the measured brick, the liquid water transport coefficient increased with a factor of 1000 when the brick became saturated. At $80 \% \mathrm{RH}$, the liquid water transport coefficient of the measured brick was similar to "Vienna 1900s brick" while it was more similar to "Masonry brick" at saturation. The moisture diffusion resistance factor, $\mu(-)$, was not measured here but is around 10-15 for most bricks [38].

The properties of the measured lime and cement mortar were similar to what is found in WUFI 2D [38] for mortars of this type. The moisture storage capacity was very similar to the measured brick shown in Figure 3. However, the maximum moisture content in the mortar was $195 \mathrm{~kg} / \mathrm{m}^{3}$ compared to $237 \mathrm{~kg} / \mathrm{m}^{3}$ in the brick. The liquid water transport coefficient was $41 \%$ lower than the brick at $80 \% \mathrm{RH}$ and $82 \%$ lower at saturation.

\subsection{Wall construction and instrumentation}

The brick wall was built inside a $3 \mathrm{~m}$ x $3 \mathrm{~m}$ steel frame to enable transport from the laboratory to the climate simulator. The lower part of the frame was filled with $200 \mathrm{~mm}$ cellular glass insulation to insulate the lower boundary of the wall from the floor. Two VIP sizes, $20 \mathrm{~mm}$ thick, were used in the study: a larger $600 \mathrm{~mm}$ x $1000 \mathrm{~mm}$ and a smaller $500 \mathrm{~mm}$ x $600 \mathrm{~mm}$. 
The size of the bricks was $226 \mathrm{~mm}$ x $104 \mathrm{~mm}$ x $60 \mathrm{~mm}$ (length x width x height) and the thickness of the mortar joints between the bricks were 10-12 mm, see Figure 9a.

Figure 9 somewhere here.

The water accumulation in the upper part of the wall could interfere with the laboratory measurement results for the lower part of the wall. Therefore a rubber strip was installed on the exterior side of the wall to stop liquid water from being transported along the wall. Mortar was applied on the entire interior brick surface to make an even surface for attaching the VIPs. Four voids of $100 \mathrm{~mm}$ x $225 \mathrm{~mm}$ each (see Figure 9c) were created where the wooden beams, made of spruce, were installed after the wall had dried. The gaps between the brick and wooden beams were sealed with a mix of modelling clay and beeswax. Underneath the beams, chipboards were installed to simulate the intermediate floor, see Figure 9d. On the chipboard between the two lower beams, a layer of glass wool was added to simulate the thermal resistance of the intermediate floor while the space around the two upper beams was left non-insulated, see Figure 9d and Figure 10. A polyethylene foil was wrapped around the beams, the chipboards and over the space between them, see Figure 9d, to simulate the vapor resistance of the intermediate floor.

Three types of sensors were installed in the wall to monitor the wetting and drying; 10 temperature and RH sensors (E+E Elektronik EE060), 8 Sahlén sensors (wood moisture sensors) and 12 resistance moisture meters (pin-type). The locations of the sensors are presented in Figure 10. The RH sensors measure the RH and temperature in the range of $0 \%$ to $100 \%$ and $-40^{\circ} \mathrm{C}$ to $60^{\circ} \mathrm{C}$. They were located in the mortar between the bricks, see Figure $9 b$, together with the Sahlén sensors. The two types of sensors were used because it was uncertain how well the RH sensors would perform in the high moisture conditions in the wall. The Sahlén sensors measure the weight percentage moisture in a piece of birch around the sensor in the range corresponding to $60 \%$ to $100 \% \mathrm{RH}$, as shown in Figure 11 . The size of the 
RH sensor is $116 \mathrm{~mm} \times 12 \mathrm{~mm}$ (height $\mathrm{x}$ diameter) and the Sahlén sensor is $40 \mathrm{~mm} \times 13 \mathrm{~mm}$ (height $\mathrm{x}$ diameter). The resistance moisture meters were made of two insulated (except at the tip) metal pins located $25 \mathrm{~mm}$ apart, and installed at three different locations in the wooden beams, as shown in Figure 10. One sensor was drilled into the center of the beam close to the interior surface of the brick (a). Two other sensors were installed $10 \mathrm{~mm}$ from the end of the beam, one in the center of the beam (b) and one on the wooden surface (c), see Figure 10. The surface sensors were made of screws instead of insulated pins. The RH sensors were monitored every 6 minutes by a computerized system. The Sahlén sensors and resistance moisture meters were monitored once a day at the start of the climate sequence, and later every 2 days.

Figure 10 somewhere here.

Figure 11 somewhere here.

\subsection{Climate sequence in the laboratory study}

After the wall was built in the laboratory it was left drying during 3 months. After that time the $\mathrm{RH}$ in the middle of the wall was around $16 \%$ and the wall was installed in the climate simulator, shown in Figure 12. In the first sequence of the laboratory study, the interior side of the brick, between the intermediate floors, was covered by VIPs, Figure 9e. The plans for the laboratory measurements in the climate simulator had to be changed during the course of running the experiment. During a test run of the climate simulator, programmed with the climate sequence defined in Figure 5, the equipment was overloaded and broke down. The rain period, which was supposed to be $4 \mathrm{~h}$, was turned off first after $14 \mathrm{~h}$ due to the equipment malfunction. It was found that the amount of rain hitting the wall was $5 \mathrm{~mm} / \mathrm{h}$, i.e. $5 \mathrm{dm}^{3} /\left(\mathrm{m}^{2} \cdot \mathrm{h}\right)$, which is twice the amount assumed in the hygrothermal numerical simulations in Section 2.4. However, from the measured climate data presented in Section 2.3, this rain load is not exceptional but very rare $[34,43]$. In the final climate sequence, presented in Table 
3 , it was decided to reduce the rain period to $0.5 \mathrm{~h}$. Furthermore, although the parametric study presented in Figure 6 showed that the solar radiation could slightly speed up the wetting of the wall, for simplicity reasons all sun load was excluded from the laboratory experiment. Finally, the exterior climate was changed to be constant at $10^{\circ} \mathrm{C}$ and $90 \% \mathrm{RH}$ and the interior climate was constant at $25^{\circ} \mathrm{C}$ and $40 \% \mathrm{RH}$.

\section{Table 3 somewhere here.}

The malfunction during the test run meant that the wall was saturated after a very short time. The water had penetrated the wall and the interior side of the wall was wet. Within less than $36 \mathrm{~h}$ all the $\mathrm{RH}$ sensors in the wall showed a $\mathrm{RH}$ of $100 \%$. The rate of capillary suction in the wall was therefore much higher than anticipated. To dry the wall, the doors to the climate simulator were opened. After 4.5 months the sensors in the wall showed a $45 \% \mathrm{RH}$ which was considered dry enough for the continuation of the study. The VIPs were installed on the interior side of the wall and the climate sequence presented in Table 3 was initiated. When all the sensors in the wall registered a $\mathrm{RH}$ above $95 \%$, the wetting sequence was stopped. After that the wall was left for drying for 1 month. At that time the VIPs on the interior side of the wall were removed and the climate was changed to allow for a faster drying. After another 2 months, the sensors in the wall were on average showing $43 \% \mathrm{RH}$ and the climate cycle in Table 3 was resumed.

Figure 12 somewhere here.

\section{Results of the laboratory measurements in the wall}

After the initial problems with the climate simulator the wall with and without VIPs were tested and the results from the laboratory measurements were compared to the numerical simulations. As presented in Table 3, the exterior climate was constant at $10^{\circ} \mathrm{C}$ and $90 \% \mathrm{RH}$ and the interior climate was constant at $25^{\circ} \mathrm{C}$ and $40 \% \mathrm{RH}$. During the first climate sequence 
the wall with interior VIPs was exposed to 2 rain events and the wall without VIPs was exposed to 3 rain events, each lasting $30 \mathrm{~min}$ with a $23.5 \mathrm{~h}$ dry period between the rain events.

\subsection{Comparison of brick wall performance with and without interior VIPs}

For the case with the VIPs on the interior, the temperature in the exterior part of the wall was expected to be lower than for the wall without VIPs. Table 4 presents the measured average temperatures in the middle of the wall and at the interior surface of the brick for the cases with and without VIPs.

Table 4 somewhere here.

The temperature is higher both in the middle of the wall and at the interior surface of the brick compared to the case with interior VIPs. The measured temperature can be compared to the calculated steady-state temperature in the wall. As presented before, the thermal conductivity of the dry bricks and VIPs was $0.6 \mathrm{~W} /(\mathrm{m} \cdot \mathrm{K})$ and $0.005 \mathrm{~W} /(\mathrm{m} \cdot \mathrm{K})$, respectively, while the surface heat transfer coefficient was assumed to be $8 \mathrm{~W} /\left(\mathrm{m}^{2} \cdot \mathrm{K}\right)$ on the interior and $25 \mathrm{~W} /\left(\mathrm{m}^{2} \cdot \mathrm{K}\right)$ on the exterior. For the case with interior VIPs, the calculated temperature in the middle of the wall was $10.8^{\circ} \mathrm{C}$ and $11.5^{\circ} \mathrm{C}$ in the interior surface of the brick. These temperatures are close to the measured temperatures. For the wall without VIPs, the calculated temperature in the middle of the wall was $16.3^{\circ} \mathrm{C}$ and $21.4^{\circ} \mathrm{C}$ on the interior surface of the brick. The interior boundary condition is of much greater importance for the latter case where the interior surface heat transfer coefficient was $22 \%$ of the total thermal resistance of the wall. Therefore, the uncertainties regarding the surface heat transfer coefficients influence the calculated temperatures in the latter case more. However, the calculated temperature for the case with VIPs showed that the measured temperature was close to what was expected. 
During the first sequence, it was noted that the RH increased more in the lower part of the wall than in the upper part, despite the rubber strip. This could be caused by the force of gravity on the liquid water flow. It could also be explained by small cracks in the wall which prolongs the time for the water to reach the sensor area in the upper part of the wall compared to those in the lower part. Another explanation could be that the rain load was non-uniformly distributed on the wall surface. The RH increase in the wall measured with the RH sensors with and without the interior VIPs is presented in Figure 13.

\section{Figure 13 somewhere here.}

It is evident that the moisture sensors in the middle of the wall (b) are reached by the moisture front faster than the sensors on the interior surface of the brick (a). In the upper part of the wall only one of the sensors reached $100 \% \mathrm{RH}$ after $30 \mathrm{~h}$. In the lower part of the wall, all four sensors had reached $100 \% \mathrm{RH}$ after $50 \mathrm{~h}$. Also in the wall without the VIPs, the difference between the upper and lower part of the wall was the same. In the upper part of the wall one of the sensors was at $100 \% \mathrm{RH}$ after $30 \mathrm{~h}$ which is the same as for the wall with VIPs. However, the RH increased faster in the lower part of the wall. All sensors had reached $100 \% \mathrm{RH}$ already after $38 \mathrm{~h}$ which is $10 \mathrm{~h}$ earlier than in the wall with interior VIPs. There is a spike in the RH after approximately 2 weeks which is caused by a power failure in the laboratory that lasted for $24 \mathrm{~h}$. During this time, the temperature could not be regulated and therefore the temperature in the inner part of the brick sank which led to an increased $\mathrm{RH}$ in the sensors in this part of the wall.

\section{Figure 14 somewhere here.}

Measurements with the Sahlén sensor, which use a piece of birch around the sensor to register the increasing moisture content, are shown in Figure 14. The Sahlén sensors showed a significantly slower increase in RH in the wall than the RH sensors in Figure 13. This is caused by the wooden material which has to absorb the moisture before it registers the 
increasing moisture content. In the upper part of the wall, the RH increased most in position 2b. This was also found with the RH sensors and could indicate that the rain load is not completely uniform on the wall.

Even though the temperature in the wall was lower in the case with interior VIPs, the RH in the upper part of the wall increased more in the wall without VIPs. For the lower part of the wall, the RH increased slower on the interior surface of the brick during the first few days, but was then equal to in the middle of the wall. The time before all sensors reached $100 \%$ was $180 \mathrm{~h}$ for the wall with interior VIPs and $170 \mathrm{~h}$ for the wall without VIPs. The faster wetting in the second case could be caused by the one more rain event in this sequence.

\subsection{Measured RH in the wooden beam ends}

The RH in the wooden beams is presented in Figure 15. As for the RH sensors and Sahlén sensors, there was a clear difference between the RH in the upper and lower part of the wall. In the beams in the upper part of the wall, the $\mathrm{RH}$ stayed below $70 \%$ during the three weeks both in the center (b) and at the surface (c) of the beam end. In the lower part of the wall, the RH increased fast and was above $90 \%$ at the surface (c) of the beam ends after $72 \mathrm{~h}$. This occurred both in the wall with and without VIPs. In the center of the beam (b), the RH increased faster in the case with the interior VIPs. However, after 1 week, the RH was the same in both cases at sensor W3b. At W4b, the RH was significantly lower during the second sequence. It could not be explained why it differed so much from the first sequence.

\section{Figure 15 somewhere here.}

The RH measured in the center of the beams at the interior part of the brick was significantly lower than at the other locations which were presented in Figure 15. However, the RH after $90 \mathrm{~h}$ was around 18 percentage points higher in the beams in the wall with VIPs. This is in line with what could be expected by the lower temperature in the wall with the interior VIPs. 
The difference between the RH in the beams in the upper and lower part of the wall could partly be caused by the glass wool insulation, which was placed in the area between the two lower beams, but not between the two upper ones. The lower temperature in the wall resulted in a higher RH in the beams in the lower part of the wall, but this effect cannot explain the large difference on its own. As discussed before, this difference could be caused by the force of gravity on the liquid water flow or a non-uniform rain load on the wall.

\subsection{Comparison of hygrothermal numerical simulations and laboratory measurements}

When comparing the laboratory measurement results with the results from the hygrothermal numerical simulations presented in Section 2.6, there is a clear discrepancy. The measured $\mathrm{RH}$ increased significantly faster than the numerical simulations predicted. As was shown in Figure 8 , the numerically simulated relative humidity increased to $100 \%$ after approximately $950 \mathrm{~h}$ in the wall without VIPs and after $700 \mathrm{~h}$ in the wall with interior VIPs. This is clearly a longer time period than the measurements showed. Using the equations from Section 2.4, the time for saturation becomes $70-130 \mathrm{~h}$ in the middle of the wall and $120-320 \mathrm{~h}$ on the interior surface of the brick, depending on the type of brick. However, the RH sensors and Sahlén sensors reached $100 \%$ after $30 \mathrm{~h}$ and $130-170 \mathrm{~h}$ in the middle of the wall and after $38-50 \mathrm{~h}$ and 170-180 $\mathrm{h}$ on the interior surface of the brick, respectively. Clearly, the brick and mortar were more capillary active than expected and the climate more severe in the laboratory study than assumed in the hygrothermal numerical simulations.

\section{Conclusions}

A brick wall with wooden beams was insulated on the interior with vacuum insulation panels (VIPs) in the laboratory. The wall was compared to the case without interior VIPs in one- and two-dimensional hygrothermal numerical simulations and laboratory measurements in a largescale building envelope climate simulator. The purpose of the one- and two-dimensional 
hygrothermal numerical simulations was to prepare the study in the climate simulator. More specifically the purpose was to estimate the influence by different brick and mortar types on the wetting and drying of the wall, to estimate the time scale of wetting, to estimate the rain load and to investigate a possible reduction of the wall thickness from $380 \mathrm{~mm}$ to $250 \mathrm{~mm}$. It was shown that adding interior VIPs could reduce the energy use substantially in brick buildings. The U-value could be reduced heavily but the thermal bridges created by the wooden beam ends and intermediate floors increased the overall U-value of the wall. The increased heat flow by wet materials in the wall was reduced after the interior VIPs were added and the U-value increased only slightly when the wall got wet.

The numerical simulations revealed that the wall could be damaged by freeze-thaw action on the exterior brick surface. The risk was highest for the wall in Bergen, since the degree of saturation was close to the critical degree of saturation. In Gothenburg, the wall did not reach as high degree of saturation but the number of freeze-thaw cycles was substantially higher. The thickness of the wall influenced the moisture accumulation rate when investigating the bricks $60 \mathrm{~mm}$ from the interior surface of the wall. The square root of the time for moisture saturation was proportional to the thickness of the brick on the exterior of the monitored position.

The moisture content in the wall was highly influenced by the properties of the brick. The time before the walls were saturated differed with a factor of 6 between the least and most permeable bricks.

The type of mortar influenced the drying of the wall. The mortar that gave the lowest drying rate was the pure cement mortar while the mixture of lime and cement gave a lower drying rate than pure lime mortar. 
The properties of the interior insulation material showed to have a lesser influence on the moisture accumulation rate. The rain load was the dominating factor determining the vapor and water transport in the wall. Having the possibility of inward drying lowered the moisture accumulation rate slightly. However, during dry periods with less rain, the VIPs reduce the drying capacity of the moisture in the brick. This could lead to prolonged periods of high moisture levels in the wooden beam ends compared to in the wall without VIPs.

The laboratory investigations showed that the relative humidity (RH) in the wall increased substantially when exposed to driving rain. As expected, the moisture increased faster in the mortar in the middle of the wall compared to on the interior surface of the brick. The brick and mortar were more capillary active than expected from the results of the numerical simulations. The lower part of the wall had a higher RH than the upper part which could be caused by the force of gravity acting on the liquid water flow or a non-uniform rain load on the wall.

The different sensors gave consistent laboratory measurement results, although the Sahlén sensor had a slower response to the increasing moisture content in the wall than the RH sensors had.

In the wooden beams, the moisture content increased more in the end of the beam than close to the interior surface of the brick, as was expected. There was no significant difference between the RH in the wooden beam ends in the case with and without VIPs. However, it was found that the temperature effect led to a higher $\mathrm{RH}$ in the wooden beam close to the interior surface of the brick and in the center of the beam end with interior VIPs.

It was difficult to predict all the uncertainties in the laboratory measurements using the hygrothermal numerical simulations. However, the cost of the experiments necessitates good preparations to minimize the number of uncertainties to control the influential parameters. Although the numerical simulation and laboratory measurement results did not converge, 
much has been learnt on how to plan and conduct these types of large-scale building envelope laboratory studies.

\section{Acknowledgements}

The work is supported by The Swedish Research Council Formas, the Lars Hierta Memorial Foundation, and finally the Research Council of Norway and several partners through The Research Centre on Zero Emission Buildings (www.ZEB.no). The laboratory measurements were performed in the laboratory of NTNU and SINTEF Building and Infrastructure in Trondheim, Norway. Øystein Holmberget and Ole Aunrønning are acknowledged for their assistance with the laboratory measurements. Porextherm Dämmstoffe $\mathrm{GmbH}$ is acknowledged for supplying the vacuum insulation panels and Wienerberger and St-Gobain Weber are acknowledged for supplying the brick and mortar.

\section{References}

[1] IEA, Policy Pathway: Modernising Building Energy Codes, Paris, France: OECD/IEA and New York, NY, USA: United Nations Development Programme (UNDP), 2013.

[2] J.-O. Dalenbäck, A. Göransson, L. Jagemar, A. Nilsson, D. Olsson, B. Pettersson, Åtgärder för ökad energieffektivisering i bebyggelse - Underlagsmaterial till Boverkets regeringsuppdrag beträffande energieffektivisering i byggnader (M2004/4246/Kb) (Measures to increase the energy efficiency in buildings - background report to Boverkets governmental mission concerning energy efficiency in buildings). [In Swedish], Chalmers University of Technology, Chalmers EnergiCentrum (CEC), Gothenburg, Sweden, 2005.

[3] Boverket, Så mår våra hus - redovisning av regeringsuppdrag beträffande byggnaders tekniska utformning m.m. (The state of our buildings - report of governmental mission on the technical design of buildings etc.). [In Swedish], Boverket, Karlskrona, Sweden, 2009. 
[4] M. Thyholt, T.D. Pettersen, T. Haavik, B.J. Wachenfeldt, Energy Analysis of the Norwegian Dwelling Stock. Subtask A - Internal working document. IEA SHC Task 37 Advanced Housing Renovation by Solar and Conservation, International Energy Agency, Solar Heating and Cooling Programme, 2009.

[5] Boverket, Regelsamling för byggande, BBR 19, 2012 (Regulations for construction, BBR 19, 2012). [In Swedish], Boverket, Karlskrona, Sweden, 2011.

[6] KRD, Byggteknisk forskrift (TEK 10). FOR-2010-03-26-489 Forskrift om tekniske krav til byggverk (Building Code. Regulations on technical requirements for construction). [In Norwegian], Kommunal- og regionaldepartementet, Bolig- og bygningsavd, Oslo, Norway, 2010.

[7] M. Morelli, L. Rønby, S.E. Mikkelsen, M.G. Minzari, T. Kildemoes, H.M. Tommerup, Energy retrofitting of a typical old Danish multi-family building to a "nearly-zero" energy building based on experiences from a test apartment, Energy and Buildings, 54 (0) (2012) 395-406.

[8] B. Weller, S. Rexroth, S. Jakubetz, Denkmal und Energie - Technologien und Systeminnovationen zur Energieversorgung und -einsparung bei Baudenkmalen (Monuments and energy - Technologies and system innovations for energy supply and conservation in historical buildings). [In German], Technische Universität Dresden, Institut für Baukonstruktion, Dresden, Germany, 2008.

[9] P. Häupl, H. Fechner, H. Petzold, Interior Retrofit of Masonry Wall to Reduce Energy and Eliminate Moisture Damage: Comparison of Modeling and Field Performance, Proceedings of Thermal Performance of the Exterior Envelopes of Whole Buildings XI, Clearwater Beach, FL, USA, December 5-9, 2010. 
[10] H. Johansson, Tilläggsisolering av tegelfasader på flerbostadshus från 1940- till 1960talet (Brick facade refurbishments of buildings from the 1940s to 1960s). [In Swedish], Bachelor's thesis, Luleå University of Technology, Department of Civil, Environmental and Natural resources engineering, Luleå, Sweden, 2011.

[11] C.-M. Capener, K. Sandin, M. Molnár, J. Jönsson, Energy efficient retrofitting of a 1950ies multi-dwelling block house considering hygrothermal properties - field measurements and simulation, Proceedings of 5th International Building Physics Conference, Kyoto, Japan, May 28-31, 2012.

[12] T.V. Rasmussen, Retrofitting Listed Buildings: Measures, Savings and Requirements, The Open Construction and Building Technology Journal, 5 (2011) 174-181.

[13] H. Künzel, Effect of interior and exterior insulation on the hygrothermal behaviour of exposed walls, Materials and Structures, 31 (2) (1998) 99-103.

[14] E. Barreira, V.P. de Freitas, Experimental study of the hygrothermal behaviour of External Thermal Insulation Composite Systems (ETICS), Building and Environment, 63 (2013) 31-39.

[15] P. Mensinga, J. Straube, C. Schumacher, Assessing the Freeze-Thaw Resistance of Clay Brick for Interior Insulation Retrofit Projects, Proceedings of Thermal Performance of the Exterior Envelopes of Whole Buildings XI, Clearwater Beach, FL, USA, December 5-9, 2010.

[16] G. Lönnroth, Kulturhistoriskt värdefull bebyggelse i Göteborg. Ett program för bevarande. Volym 1 del 2 (Cultural heritage buildings in Gothenburg. A program for conservation. Volume 1 part 2). [In Swedish], City of Gothenburg, City planning office, Gothenburg, Sweden, 1999. 
[17] Boverket, Energi i bebyggelsen - tekniska egenskaper och beräkningar - resultat från projektet BETSI (Energy in the built environment - technical properties and calculations results from the BETSI study). [In Swedish], Boverket, Karlskrona, Sweden, 2010.

[18] J. Straube, K. Ueno, C. Schumacher, Internal Insulation of Masonry Walls: Final Measure Guideline, Prepared for U.S. Department of Energy, Office of Energy Efficiency and Renewable Energy, Somerville, MA, USA, 2012.

[19] D. Kehl, U. Ruisinger, R. Plagge, J. Grunewald, Wooden beam ends in masonry with interior insulation - A literature review and simulation on causes and assessment of decay, Proceedings of 2nd Central European Symposium on Building Physics, Vienna, Austria, September 9-11, 2013.

[20] T. Van den Brande, B. Blocken, S. Roels, Rain water runoff from porous building facades: Implementation and application of a first-order runoff model coupled to a HAM model, Building and Environment, 64 (2013) 177-186.

[21] C. Hall, Water movement in porous building materials - I. Unsaturated flow theory and its applications, Building and Environment, 12 (2) (1977) 117-125.

[22] H.J.P. Brocken, Moisture Transport in Brick Masonry: The Grey Area Between Bricks, PhD Dissertation, Eindhoven University of Technology, Faculty of Architecture, Building and Planning, and Faculty of Applied Physics, Eindhoven, The Netherlands, 1998.

[23] M. Abuku, B. Blocken, S. Roels, Moisture response of building facades to wind-driven rain: field measurements compared with numerical simulations, Journal of Wind Engineering and Industrial Aerodynamics, 97 (5-6) (2009) 197-207.

[24] J.C.Z. Piaia, M. Cheriaf, J.C. Rocha, N.L. Mustelier, Measurements of water penetration and leakage in masonry wall: Experimental results and numerical simulation, Building and Environment, 61 (2013) 18-26. 
[25] R. Baetens, B.P. Jelle, J.V. Thue, M.J. Tenpierik, S. Grynning, S. Uvsløkk, A. Gustavsen, Vacuum insulation panels for building applications: A review and beyond, Energy and Buildings, 42 (2) (2010) 147-172.

[26] S.E. Kalnæs, B.P. Jelle, Vacuum insulation panel products: A state-of-the-art review and future research pathways, Applied Energy, 116 (0) (2014) 355-375.

[27] E. Sveipe, B.P. Jelle, E. Wegger, S. Uvsløkk, S. Grynning, J.V. Thue, B. Time, A. Gustavsen, Improving thermal insulation of timber frame walls by retrofitting with vacuum insulation panels - experimental and theoretical investigations, Journal of Building Physics, 35 (2) (2011) 168-188.

[28] R. Pfluger, W. Hasper, B. Schulze Darup, D. Sommer, M. Forstner, Wissenschaftlige Analyse eines auf vorgefertigten Vakuum-Paneel-Verbundplatten beruhenden Innendämmsystems. Abschlussbericht (Scientific analysis of an interior insulation system based on prefabricated vacuum insulation composite panels. Final report). [In German], VARIOTEC GmbH \& Co.KG, Neumarkt, Germany, 2008.

[29] E. Wegger, B.P. Jelle, E. Sveipe, S. Grynning, A. Gustavsen, R. Baetens, J.V. Thue, Aging effects on thermal properties and service life of vacuum insulation panels, Journal of Building Physics, 35 (2) (2011) 128-167.

[30] S. Brunner, H. Simmler, In situ performance assessment of vacuum insulation panels in a flat roof construction, Vacuum, 82 (7) (2008) 700-707.

[31] S. Brunner, K. Ghazi Wakili, Hints for an additional aging factor regarding the thermal performance of vacuum insulation panels with pyrogenic silica core, Vacuum, 100 (0) (2014) 4-6.

[32] K. Ueno, Masonry Wall Interior Insulation Retrofit Embedded Beam Simulations, Proceedings of Building Enclosure Science \& Technology Conference, BEST 3: High 
Performance Buildings - Combining Field Experience with Innovation, Atlanta, GA, USA, April 2-4, 2012.

[33] T.V. Rasmussen, Post-Insulation of Existing Buildings Constructed Between 1850 and 1920, Proceedings of Thermal Performance of the Exterior Envelopes of Whole Buildings XI, Clearwater Beach, FL, USA, December 5-9, 2010.

[34] A. Högberg, Microclimate Load: Transformed Weather Observations for Use in Durable Building Design, PhD Dissertation, Chalmers University of Technology, Department of Building Physics, Gothenburg, Sweden, 2002.

[35] Angelantoni Industrie S.p.A., Double room test equipment for building walls thermal performance testing Mod. UC2x18 RT/SR, Angelantoni Industries S.p.A., Massa Martana, Italy, n.d.

[36] T. Kvande, K.I. Edvardsen, Eldre yttervegger av mur og betong. Metoder og materialer (Older exterior brick and concrete walls. Methods and materials). [In Norwegian], SINTEF Building and Infrastructure, Oslo, Norway, 2013.

[37] M. Morelli, S. Svendsen, Investigation of interior post-insulated masonry walls with wooden beam ends, Journal of Building Physics, 36 (3) (2013) 265-293.

[38] Fraunhofer IBP, WUFI 2D Transient Heat and Moisture Transport, Vers. 3.3.2, Fraunhofer IBP, Holzkirchen, Germany, 2010.

[39] NS-EN ISO 15148:2002. Hygrothermal performance of building materials and products Determination of water absorption coefficient by partial immersion, International Organization for Standardization (ISO), Geneva, Switzerland, 2002.

[40] NS-EN 1015-18:2002. Methods of test for mortar for masonry - Part 18: Determination of water absorption coefficient due to capillary action of hardened mortar, European Committee for Standardization (CEN), Brussels, Belgium, 2002. 
[41] Brick Industry Association, Manufactoring of Brick, The Brick Industry Association, Reston, Virginia, USA, 2006.

[42] Brick Industry Association, Mortars for Brickwork - Selection and Quality Assurance, The Brick Industry Association, Reston, Virginia, USA, 2006.

[43] K. Nore, B. Blocken, B.P. Jelle, J.V. Thue, J. Carmeliet, A dataset of wind-driven rain measurements on a low-rise test building in Norway, Building and Environment, 42 (5) (2007) 2150-2165.

[44] SS-EN 15026:2007. Hygrothermal Performance of Building Components and Elements — Assessment of Moisture Transfer by Numerical Simulation, European Committee for Standardization, Brussels, Belgium, 2007.

[45] SS-EN ISO 6946:2007. Building components and building elements - Thermal resistance and thermal transmittance - Calculation method, International Organization for Standardization (ISO), Geneva, Switzerland, 2007.

[46] A. Danielsson, A.S. Wannerskog, L. Thuvander, Case Torpa (Report), Chalmers University of Technology, Department of Architecture, Gothenburg, Sweden, 2013.

[47] C.-E. Hagentoft, A.S. Kalagasidis, B. Adl-Zarrabi, S. Roels, J. Carmeliet, H. Hens, J. Grunewald, M. Funk, R. Becker, D. Shamir, O. Adan, H. Brocken, K. Kumaran, R. Djebbar, Assessment Method of Numerical Prediction Models for Combined Heat, Air and Moisture Transfer in Building Components: Benchmarks for One-dimensional Cases, Journal of Thermal Envelope and Building Science, 27 (4) (2004) 327-352. 


\section{Figure captions}

Figure 1. Left: Lyckholms brewery in Gothenburg built in the late 1880s is listed for its characteristic exterior expression, which excludes exterior insulation as an option. Right: connection of a wooden beam in a brick wall.

Figure 2. Left: schematics of a brick wall with a wooden beam installed in the brick. The black horizontal lines through the insulation layer marks the $300 \mathrm{~mm}$ wide non-insulated area above and below the beam, described in the main text. Right: one- and two-dimensional numerical simulation models of the wall. 1) $380 \mathrm{~mm}$ thick brick wall with $10-12 \mathrm{~mm}$ mortar between the bricks (2D), 2) brick wall without mortar (1D), 3) $250 \mathrm{~mm}$ thick brick wall with 10-12 mm mortar between the bricks (1D), 4) $250 \mathrm{~mm}$ brick wall with $10-12 \mathrm{~mm}$ mortar between the bricks (2D).

Figure 3. Moisture sorption isotherms at $23^{\circ} \mathrm{C}$ of four types of brick investigated in the numerical simulation study ${ }^{\mathrm{a}}$, and a historical brick from the early 1900s in Vienna based on data from WUFI 2D [38]. The measured sorption isotherm for the brick used in the laboratory study is presented for comparison. It is created using the measured moisture content at saturation and Equation (2).

Figure 4. Numerically simulated RH in the middle of the wall (marked by the cross with a circle on the right) and the total moisture content (MC) in the wall. The wall was composed of $380 \mathrm{~mm}$ thick homogenous "Extruded brick".

Figure 5. Applied interior and exterior climates for the hygrothermal numerical simulations of the brick wall in a 120 hour cycle based on the climate used in the HAMSTAD benchmark project [47]. 
Figure 6. Numerically simulated RH $60 \mathrm{~mm}$ from the interior surface of the brick (marked by the cross with a circle on the right) in the two brick walls with different thicknesses. The walls were composed of either "Historical brick" or "Masonry brick", defined in Table 1, during the applied climate cycle given in Figure 5. As comparison, the $250 \mathrm{~mm}$ and $380 \mathrm{~mm}$ thick "Masonry brick" walls were also simulated without the solar radiation (dotted lines) in Figure 5 .

Figure 7. Numerically simulated RH in the middle of the mortar (marked by the cross with a circle on the right), starting at $98 \% \mathrm{RH}$, in a $250 \mathrm{~mm}$ "Extruded brick" (B) wall with different types of mortar (C/LC/L). For comparison a wall with only "Extruded brick" was numerically simulated at the same conditions. The walls were placed indoors in the laboratory for drying.

Figure 8. Left: numerically simulated RH $60 \mathrm{~mm}$ from the interior surface of the brick (marked by the cross with a circle next to the curves). Right: numerically simulated total moisture content in a $250 \mathrm{~mm}$ thick wall.

Figure 9. Photos from the construction of the wall in the laboratory of NTNU and SINTEF Building and Infrastructure. a: brick and mortar laid out, b: RH sensor (marked by the arrow) installed in the mortar in the middle of the wall, c: finished brick wall with the four voids for the wooden beams marked with black rectangles, d: wooden beams, made of spruce, and chipboards installed and wrapped in polyethylene foil, e: installation of the VIP which were glued to the wall with taped edges.

Figure 10. Left: measurements of the wall with the locations and sizes of the VIPs and sensor positions. $\mathrm{RH}=\mathrm{RH}$ sensors, $\mathrm{S}=$ Salén sensors and $\mathrm{W}=$ resistance moisture meters. A layer of glass wool was located around the two lower wooden beams. The horizontal dashed black line shows the symmetry line of the wall where a rubber strip was installed on the exterior surface of the wall to break the water run-off. Right: the sensor locations in the wooden beams (spruce) at different depths of the wall, indicated by a, b and c. 
Figure 11. Moisture sorption isotherms for birch (in the Sahlén sensor) and spruce (in the wooden beams) for expressing the measured weight percentage moisture content as RH.

Figure 12. The large-scale building envelope climate simulator in the laboratory of NTNU and SINTEF Building and Infrastructure with the brick wall installed between the interior and exterior climate chambers.

Figure 13. Measured RH in the wall. Top left: with interior VIPs in the upper part of the wall. Top right: without interior VIPs in the upper part of the wall. The sensors are located in the mortar in the middle of the wall (RH1b, RH2b) and in the mortar on the interior surface of the brick (RH1a, RH2a). Bottom left: with interior VIPs in the lower part of the wall. Bottom right: without VIPs in the lower part of the wall. The sensors are located in the mortar in the middle of the wall (RH3b, RH4b) and in the mortar on the interior surface of the brick (RH3a, $\mathrm{RH} 4 \mathrm{a})$.

Figure 14. Measured moisture content with the Sahlén sensors expressed as RH by using the sorption isotherm for birch. Top left: with interior VIPs in the upper part of the wall. Top right: without interior VIPs in the upper part of the wall. The sensors are located in the mortar in the middle of the wall (S1b, S2b) and in the mortar on the interior surface of the brick (S1a, S2a). Bottom left: with interior VIPs in the lower part of the wall. Bottom right: without VIPs in the lower part of the wall. The sensors are located in the mortar in the middle of the wall $(\mathrm{S} 3 \mathrm{~b}, \mathrm{~S} 4 \mathrm{~b})$ and in the mortar on the interior surface of the brick (S3a, S4a).

Figure 15. Measured moisture content in the wooden beams (spruce) expressed as RH by using the sorption isotherm for spruce. Left: with interior VIPs. Right: without VIPs. The resistance moisture meters are located in the center of the beam end (b) and at the surface of the beam end (c). The beams in the upper part of the wall are non-insulated and the beams in the lower part are insulated with glass wool in the area between the beams. 
Table 1. Hygrothermal properties of four types of brick and six types of mortar used in the numerical simulation study, and a historical brick from the early 1900s in Vienna based on data from WUFI 2D [38]. Also, one brick and mortar with properties measured in the laboratory ${ }^{\mathrm{a}}$ are included as comparison.

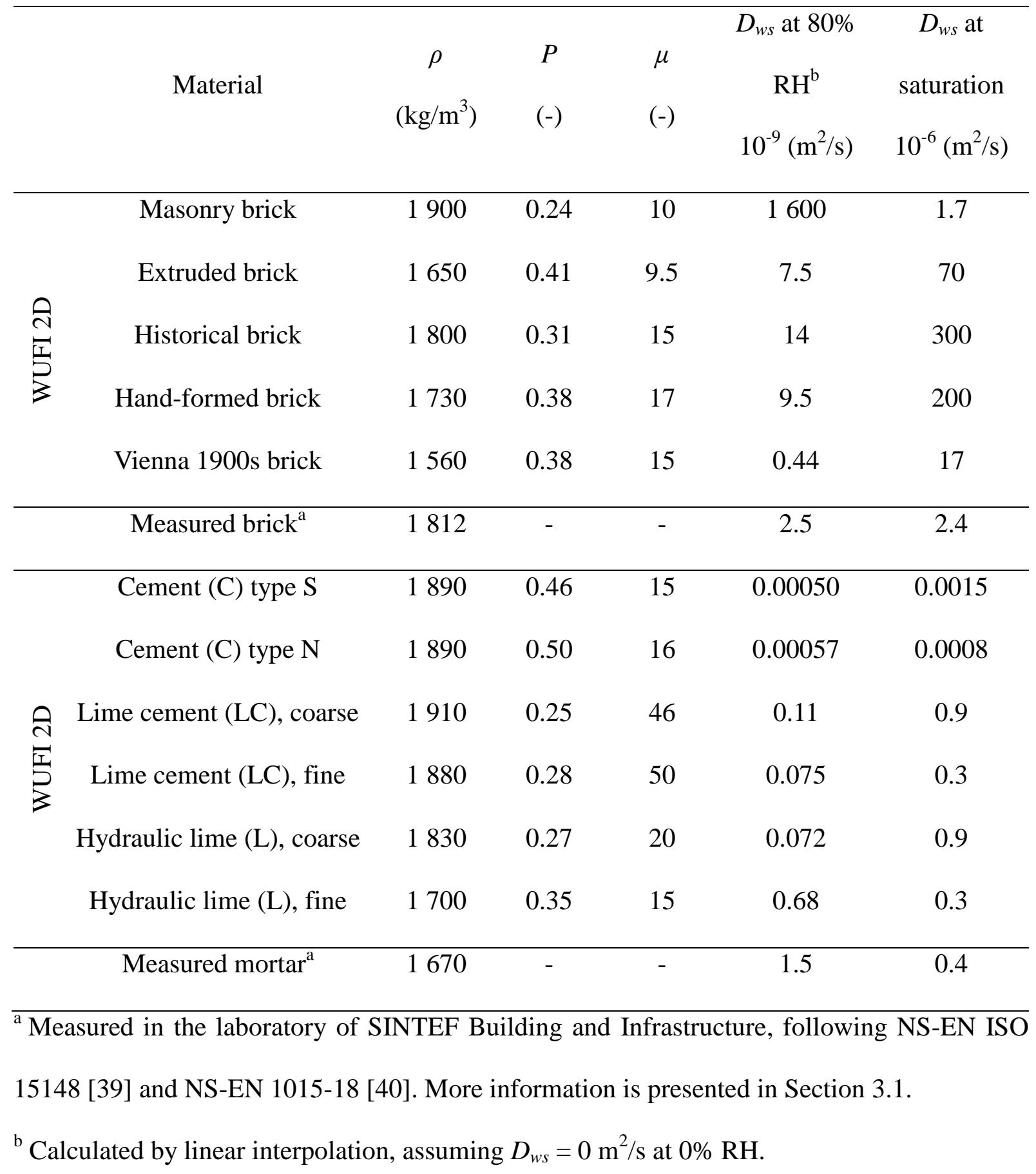


Table 2. Measured hygrothermal properties of the brick and mortar used in the laboratory study. The uncertainties are given as the standard deviation of the mean with a confidence interval of $68.3 \%$.

\begin{tabular}{ccccc}
\hline Material & $\rho$ & $A_{w}$ & Moisture content at & Moisture content at \\
& $\left(\mathrm{kg} / \mathrm{m}^{3}\right)$ & $\left(\mathrm{kg} /\left(\mathrm{m}^{2} \cdot \mathrm{s}^{0.5}\right)\right)$ & $75 \% \mathrm{RH}(\mathrm{wt} \%)$ & saturation $(\mathrm{wt} \%)$ \\
\hline Brick & $1810 \pm 30$ & $0.19 \pm 0.03$ & $0.046 \pm 0.004$ & $13.1 \pm 0.6$ \\
Mortar & $1670 \pm 40$ & $0.0655 \pm 0.0004$ & $2.04 \pm 0.08$ & $11.7 \pm 0.2$ \\
\hline
\end{tabular}


Table 3. Final climate sequence used in the laboratory simulator. Before the sequence was started the wall was dried in the laboratory for 4.5 months until all the sensors in the wall showed below $45 \%$ RH.

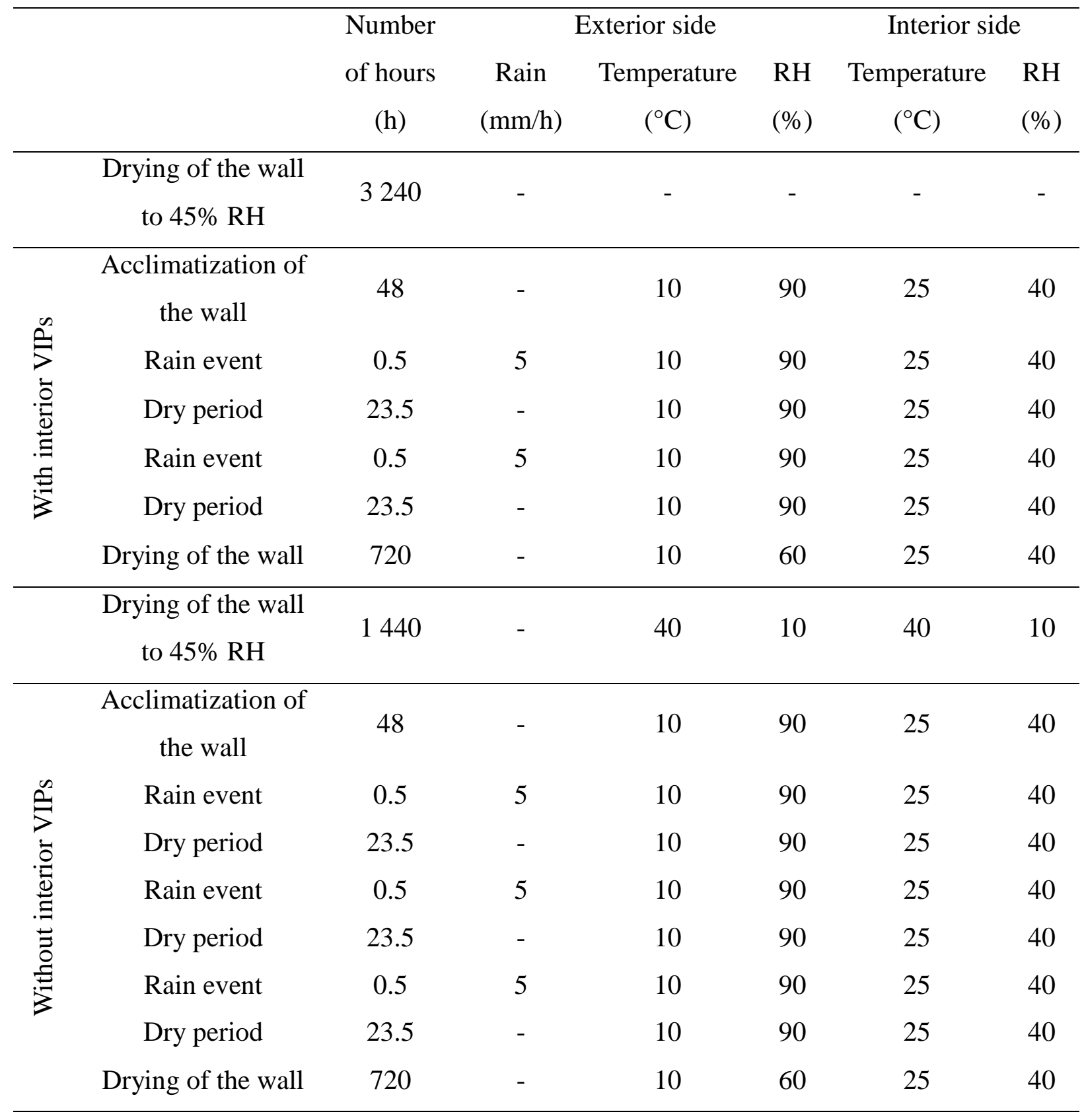


Table 4.Temperature on the interior and exterior side of the wall and the average measured temperatures in the middle of the wall and at the interior surface of the brick. The calculated temperatures, based on tabulated material data, are presented as comparison.

\begin{tabular}{|c|c|c|c|c|c|}
\hline & Exterior side & Middle of the wall & Interior surface & Interior side \\
\hline & & $\left({ }^{\circ} \mathrm{C}\right)$ & $\left({ }^{\circ} \mathrm{C}\right)$ & of the brick $\left({ }^{\circ} \mathrm{C}\right)$ & $\left({ }^{\circ} \mathrm{C}\right)$ \\
\hline \multirow{4}{*}{ 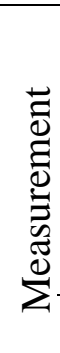 } & Wall with VIPs & 10 & 10.6 & 10.9 & 25 \\
\hline & Wall without & & & & \\
\hline & & 10 & 13.7 & 15.9 & 25 \\
\hline & Difference & - & 3.0 & 5.0 & - \\
\hline \multirow{4}{*}{ 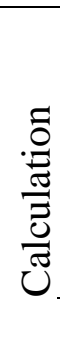 } & Wall with VIPs & 10 & 10.8 & 11.5 & 25 \\
\hline & Wall without & & & & \\
\hline & VIPs & 10 & 16.3 & 21.4 & 25 \\
\hline & Difference & - & 5.5 & 9.9 & - \\
\hline
\end{tabular}


Figure 1

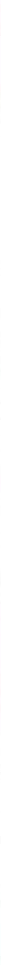


Interior plaster/ adjustment layer

Wooden floor beams $100 \times 225 \mathrm{~mm}$

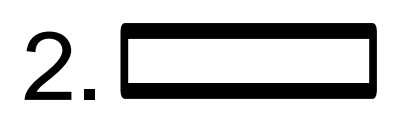

Homogenous brick

$3 . \square$ wall $380 \mathrm{~mm}$

VIP e.g. $20 \mathrm{~mm}$

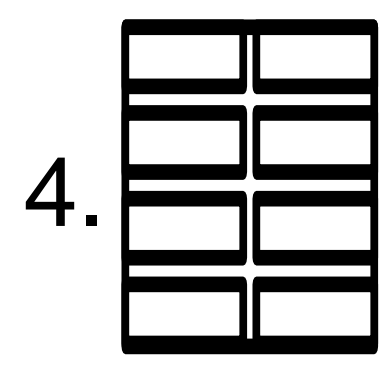

$200 \mathrm{~mm}$ 


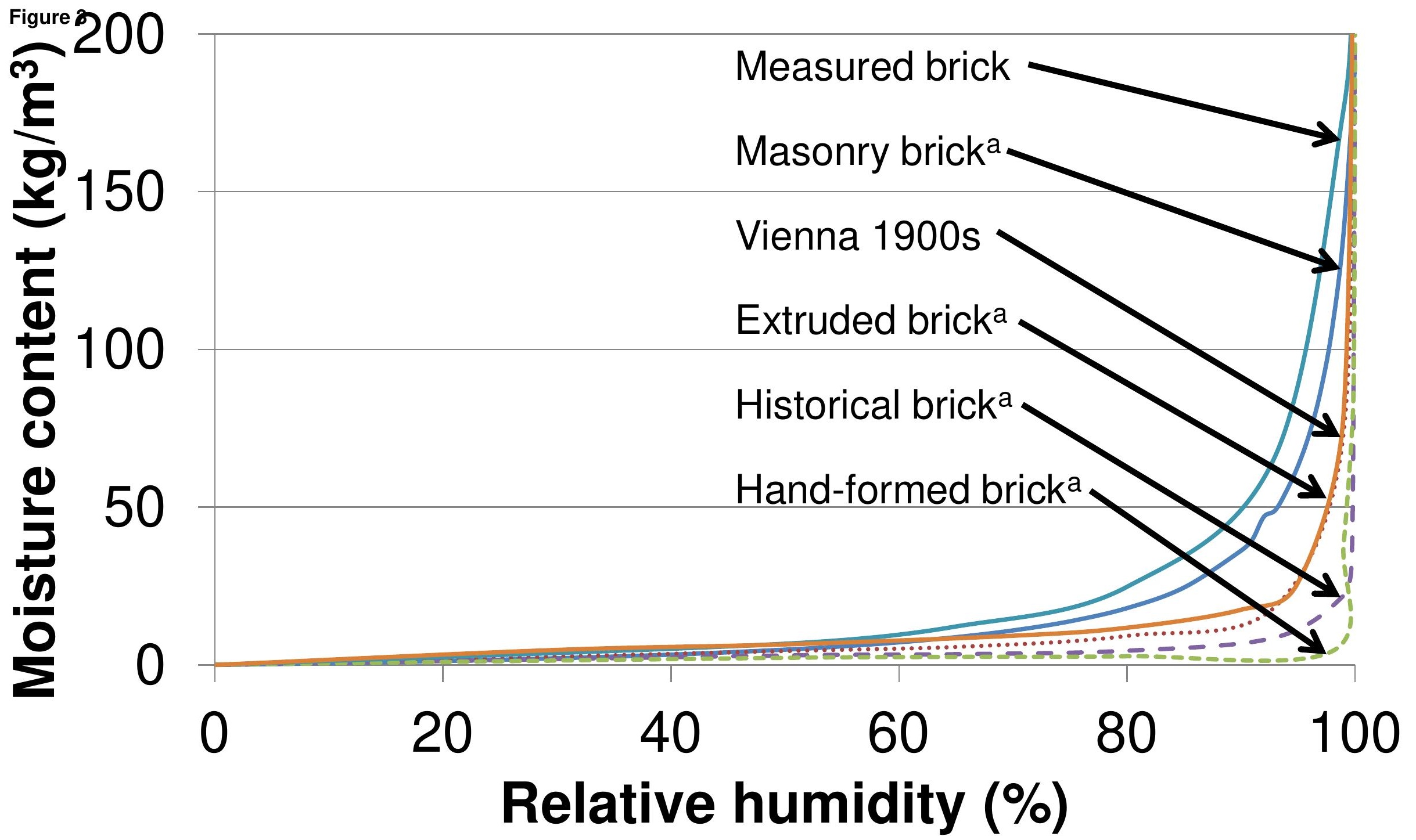

Measured brick

Masonry brick ${ }^{\mathrm{a}}$

Vienna 1900s

Extruded brick ${ }^{\mathrm{a}}$

Historical brick ${ }^{\mathrm{a}}$

Hand-formed brick ${ }^{a}$ 


\section{○ 90 RH Bergen}

בְ

60

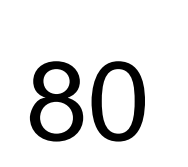

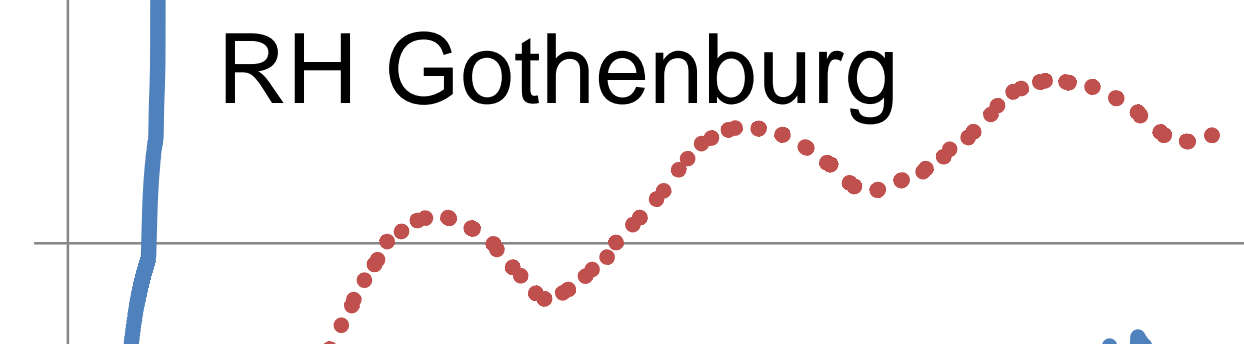

70

50 MC Gothenburg

50

40

0
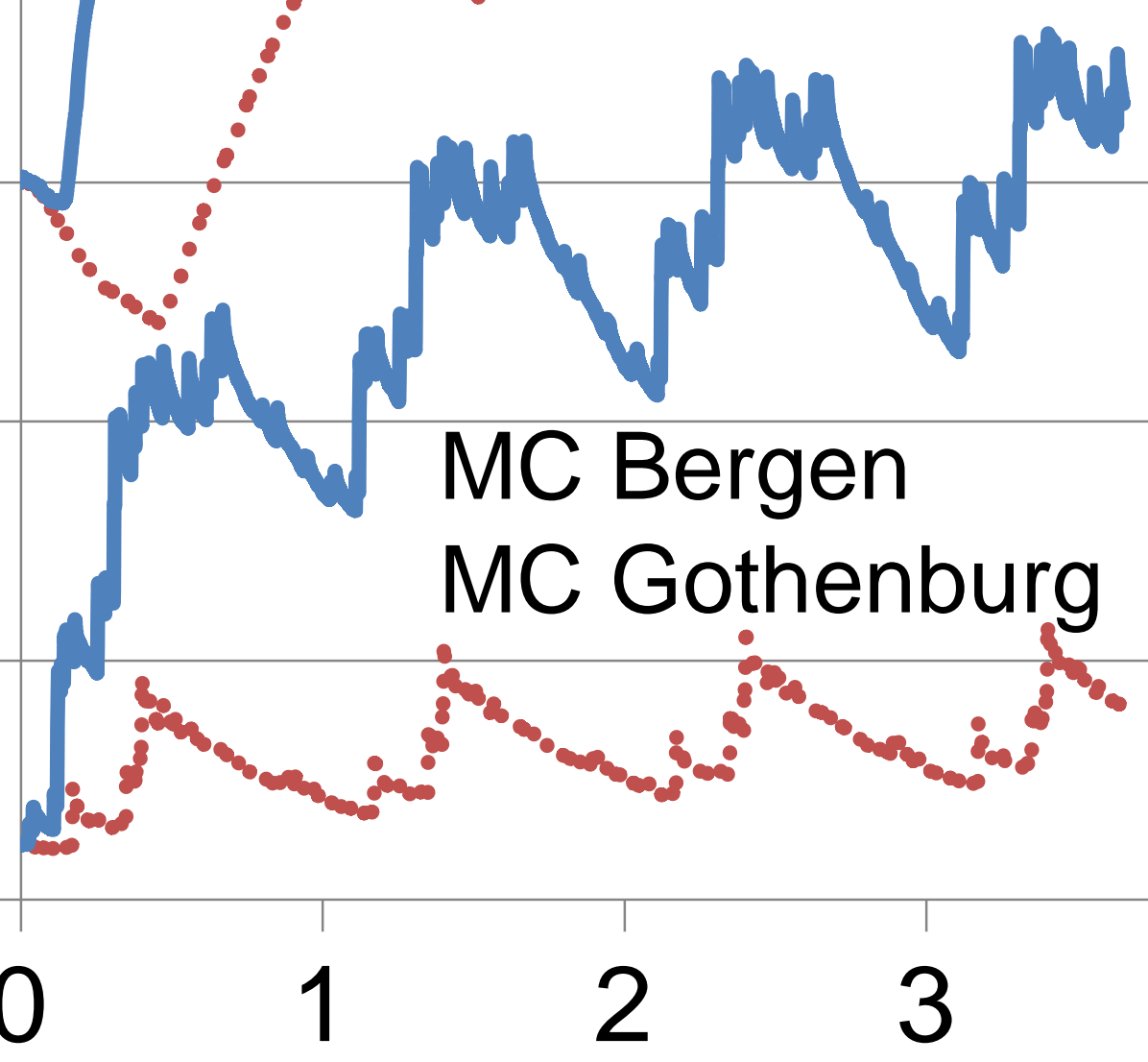

MC Bergen

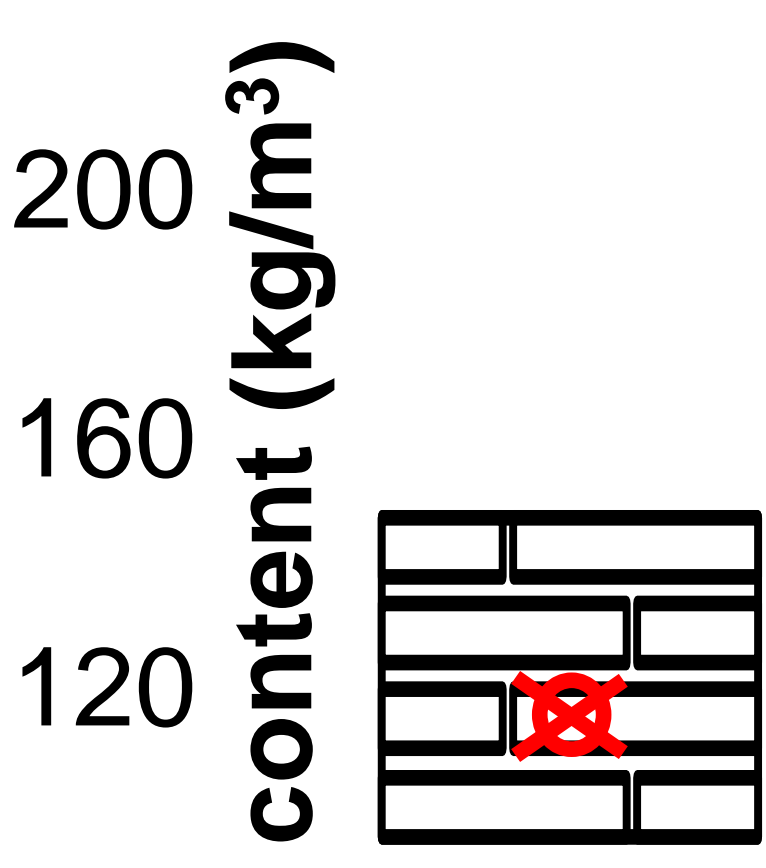

80

(1)

5

40

2

0

Number of years 


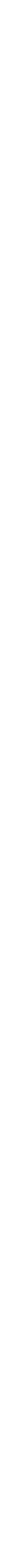




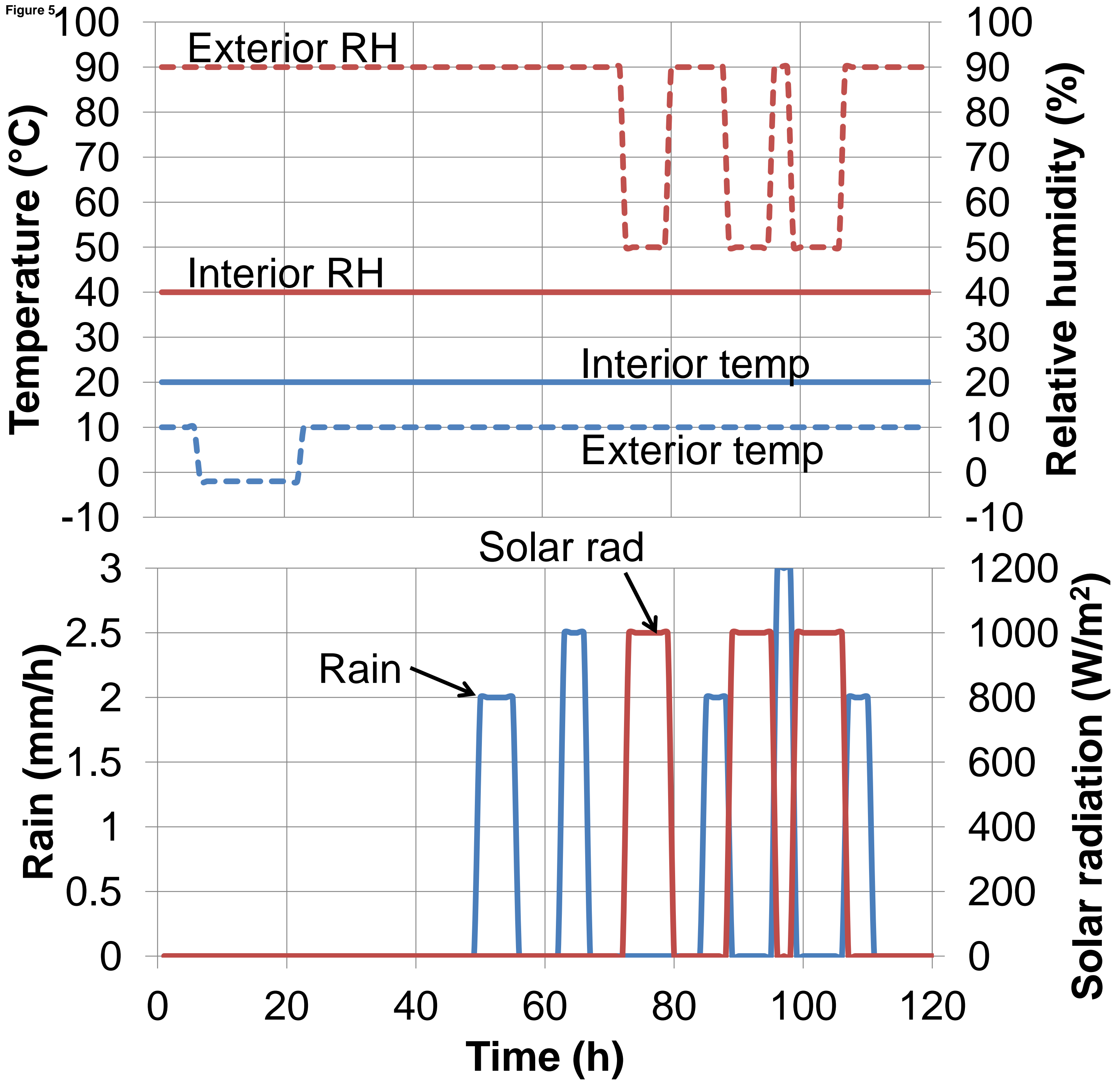

90 - Exterior RH

(ิ) 80

70

ఏ 60

50

40

30

20

Interior temp

10

0

Solar rad

Exterior temp

1200

1000

800

600

400

200

0

,

Time (h) 


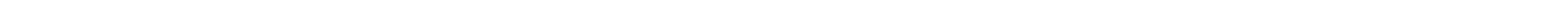




\section{(Resistance moisture meter)}

0

\section{0}

40

60

80

100

\section{Relative humidity (\%)}

\section{Birch}

(Sahlén sensor) 
Figur $\$ 00$

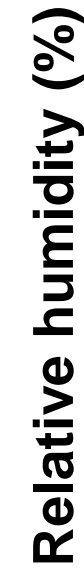

40

20

0

בְ
Upper, with VIPs
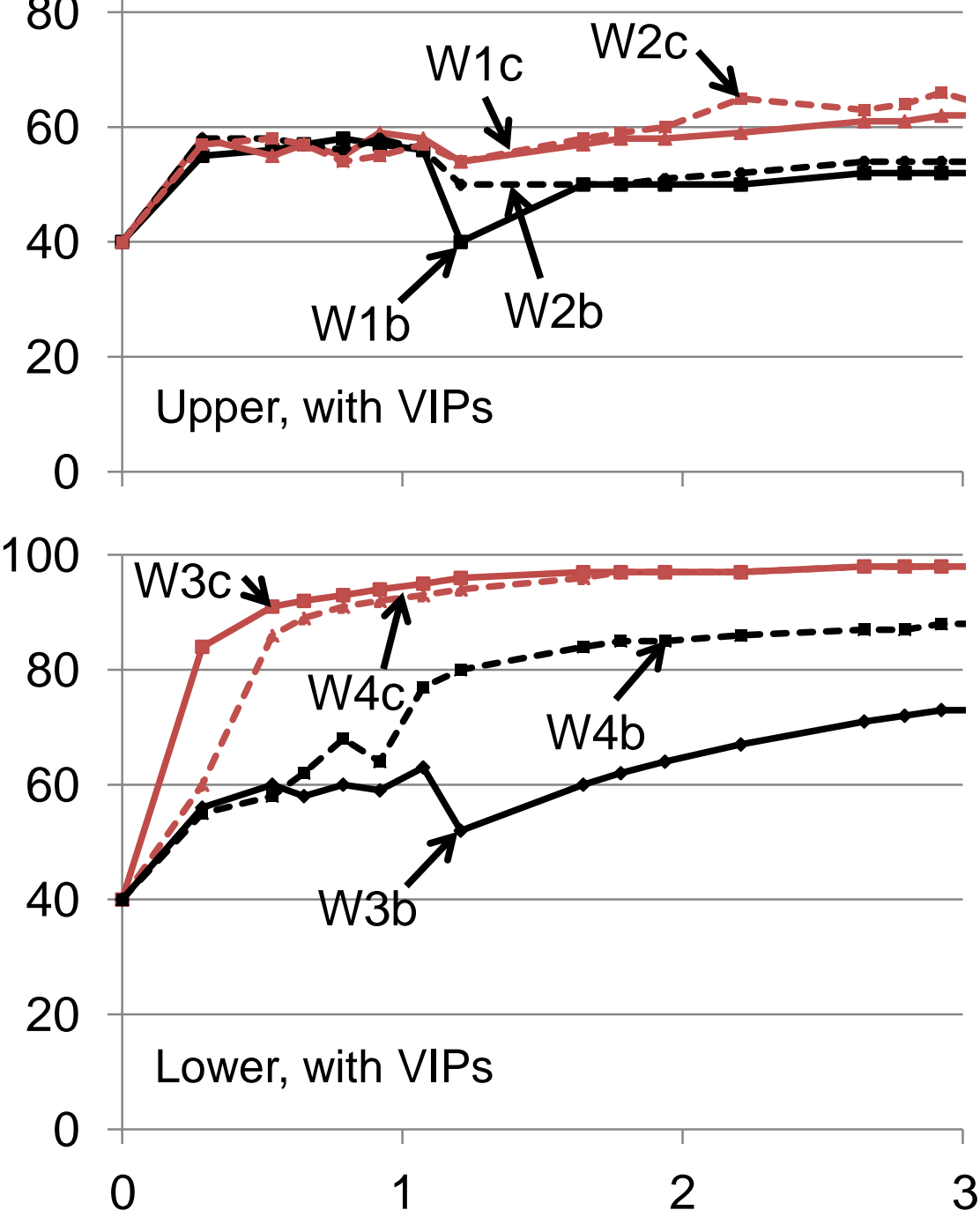

Number of weeks

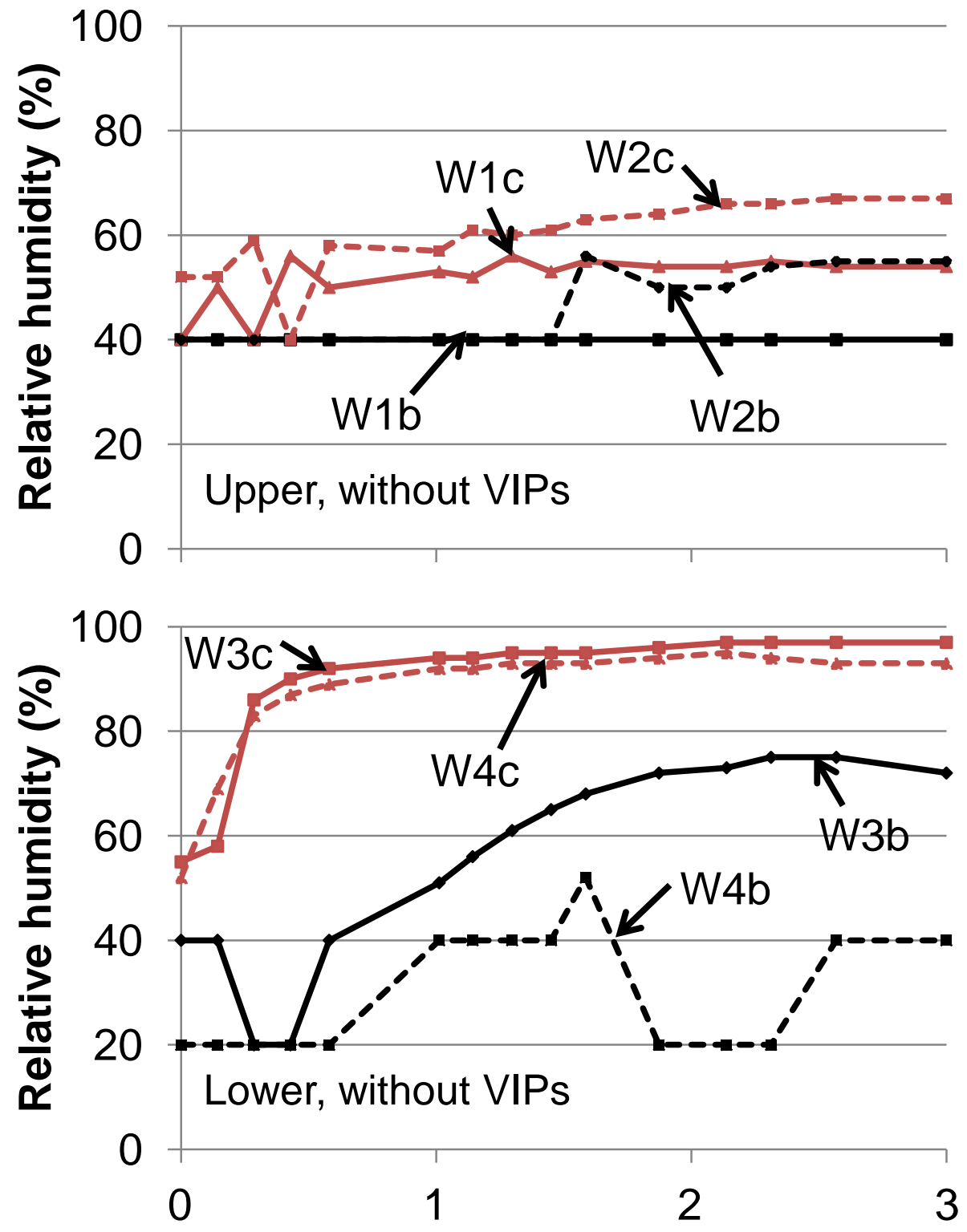

Number of weeks 